\title{
The "Kamasutra" temples of India: A case for the encoding of psychedelically induced spirituality
}

\author{
MEENA MAILLART-GARG ${ }^{1}$ and MICHAEL WINKELMAN ${ }^{2 *}$ \\ ${ }^{1}$ Linguistics and Phonetic, The English and Foreign Languages University, Hyderabad, India \\ ${ }^{2}$ Retired, School of Human Evolution and Social Change, Arizona State University, Tempe, AZ, USA
}

(Received: August 13, 2018; accepted: February 26, 2019)

\begin{abstract}
The essay proposes that entheogenic mushrooms and shamanic experiences are encoded in the Khajuraho Temples of India. Erotic sculptures of Khajuraho have statues with limbs depicted in strange positions, separated from the body or with orientations that are anatomically impossible. These represent dismemberment experiences typical of shamanic and mystical initiation, a phenomenon with precedents in Hindu and Buddhist traditions. The central placement of mushroom depictions in the temple structures indicates that their identities should be sought among entheogenic mushrooms, but features that could distinguish entheogenic mushroom species are often ambiguous. Nonetheless, the centrality of their placement supports the entheogenic hypothesis. While the presence of multiple fungi and plant sources for soma seems likely, the argument for the originality of Amanita muscaria is made in assessing the principal names of the God Vishnu with respect to features of the mushroom. Various associations of the Gods at Khajuraho and other sites suggest the broad identification of Hindu Gods with entheogenic mushrooms. Icons of mushroom are also secretly encoded in the Khajuraho sculptures in association with the so-called vandalized or broken sculptures of Khajuraho. A repeated "figure 8" pattern suggests that the artists deliberately constructed them to appear vandalized in order to encode information depicting the early stage of $A$. muscaria and other entheogenic fungi. These encoded figures provide support for the argument that A. muscaria, Hindu God Vishnu, Jain Mahaveera, and the Buddha (and perhaps other Gods and Goddesses of Vedic/Jain/Hindu/Buddhist pantheon) could be interconnected. This paper concludes with an assessment of the implications of this entheogenic evidence for the reinterpretation of central aspects of religious beliefs and ideologies of India.
\end{abstract}

Keywords: Khajuraho, soma, Vishnu, entheogens, shamanism, spirituality

\section{INTRODUCTION}

This essay presents a study of the presence of entheogenic mushroom representations in the sculptural iconography of some ancient temples of India, the Khajuraho Temples, and their sanctuaries. The essay proposes that entheogenic mushrooms and shamanic experiences are encoded in the representations of the Khajuraho Temples. Examination of erotic sculptures of Khajuraho shows that the body parts of the "people" depicted in the statues have twists and turns, which are anatomically impossible for the human body. These sculptures therefore do not merely depict humans and their sexual orgies that they appear. Instead these disjointed limbs seem to be depicting the dismemberment experiences typical of shamanic and mystical initiation reported around the world. This shamanic dismemberment phenomenon also has precedents in Hindu and Buddhist traditions, emphasizing the hidden spiritual messages in the Khajuraho sculptures.

The temple sculptures and structures also prominently display mushrooms. Their central placement indicates that their identities should be sought among entheogenic mushrooms. A review of the physical features of $A$. muscaria and other entheogenic fungi is proposed as a basis for identifying the features of the mushrooms in sculptures. Our considerations begin with $A$. muscaria (L. ex. Fr.) Persoon ex
W. J. Hooker, which Wasson $(1968,1971)$ famously proposed as the sacrament soma of Hindu spiritual traditions. Features of principal entheogenic mushroom species are compared to some of the principal mushrooms depicted at the sanctuaries of the temples. The features distinguishing entheogenic mushroom species are limited and often appear ambiguous, but the centrality of their placement supports the entheogenic hypothesis.

While the presence of multiple fungi and plant sources for soma seems likely, the argument for the originality of $A$. muscaria is made in assessing the principal names of the God Vishnu with respect to the key features of the mushroom to illustrate the specificity of evidence for the soma hypothesis. Various associations of the Gods at Khajuraho and other sites suggest the broad identification of Hindu Gods with entheogenic mushrooms. Evidence is found in analysis of the mythology and sacred scriptures of Hinduism, which indicates that icons of mushroom are also secretly encoded in the Khajuraho sculptures in association with the so-called vandalized or broken sculptures of

\footnotetext{
* Corresponding author: Michael Winkelman; Caixa Postal 62 Pirenopolis, Go. 72980-000, Brazil; Phone: +1 623239 1662; E-mails: kamasutratemples@gmail.com; michaeljwinkelman@ gmail.com
}

This is an open-access article distributed under the terms of the Creative Commons Attribution-NonCommercial 4.0 International License, which permits unrestricted use, distribution, and reproduction in any medium for non-commercial purposes, provided the original author and source are credited, a link to the CC License is provided, and changes - if any - are indicated. 
Khajuraho. A repeated pattern of apparent damage suggests that some are not actually damaged, but that the artists deliberately constructed them to appear vandalized in order to encode information related to entheogens, namely the "figure 8" of the early stage of A. muscaria and other entheogenic fungi. These encoded figures provide support for the argument that A. muscaria, Vishnu, Jain Mahaveera, the Buddha (and perhaps other Gods and Goddesses of Jain/Hindu/Buddhist pantheon) could be interconnected. The paper concludes with an assessment that the implications of this entheogenic evidence for the reinterpretation of central aspects of religious beliefs and ideologies of India.

\section{THE KHAJURAHO TEMPLES}

The Khajuraho Temples, popularly known as the Kamasutra temples of India, have aroused curiosity with their seemingly brazen depictions of erotica. These magnificent temples were built by the Chandellas, between AD 900 to 1130, in an imposing city spread over 21 square kilometers, called "Kharjjura-vaahaka," which the Chandellas exalted as one of their capitals (Mitra, 2002). This place is located within the Chhattarpur District of the state of Madhya Pradesh in central India. The ancient name of the city "Kharjjura-vaahaka" has two meanings: "the scorpion bearer" and "Date Palm" or Phoenix dactylifera (Desai, 1996). Monier-Williams Sanskrit-English Dictionary (1899) gives "drona" as a meaning of "scorpion" (98009) (ID numbers refer to meanings from Monier-Williams' Sanskrit-English Dictionary), which also means "a soma vessel" (98002). Therefore, "scorpion" can be an icon of soma, and the "scorpion bearer" of Khajuraho can be $A$. muscaria, personified as the skeleton of Goddess Chamunda, depicted with a scorpion in her belly. Curiously, Michel Postel notes in his foreword to Desai's "The Religious Imagery of Khajuraho" that some of the female figures "undressing" on the pretext of removing scorpions from their bodies have the word "sri" inscribed on their thighs. Now, "sri" (222857) has the interesting meanings: "Lakshmi" (wife of Vishnu), "Saraswati" (Goddess of knowledge), a "flame," and a "kind of drug." All these meanings are intriguing and point toward the symbolic importance of the iconography of "scorpion."

The sculptures on the outer walls of the Khajuraho Temples are quite far from the visitor and their details are visible only through a high-resolution camera. With bare eyes, one can only conclude that the sculptures exhibit sexual activities of humans, and that some of them are broken.

These sculptures present conceptual challenges for several reasons. First, the erotic scenes are present in sacred places that have traditions of asceticism and celibacy. Second, these sculptures, which possess incredible aesthetic appeal, are marred by bizarre postures and mutilations or apparent damage. Analysis of the anatomical aberrations in the sculptures reveals that the artists are creating an illusion within the figures of copulation and sexual orgies, depicting impossible configurations of human anatomy. These dismembered limbs have precedents in shamanism, Hinduism, and Buddhism as symbols of spiritual transformation that we discuss in the following sections.

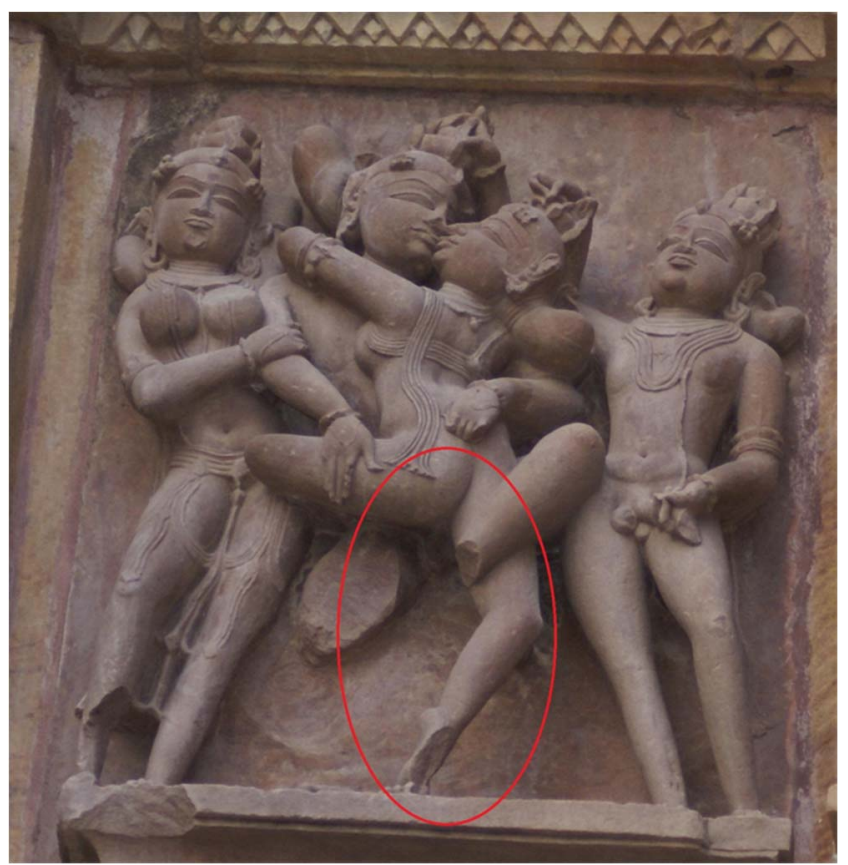

Figure 1. Kandariya Mahadeva Temple, Khajuraho

\section{Dismembered erotic sculptures of the Khajuraho Temples}

A number of the erotic sculptures present figures that have their limbs separated from the body and in impossible orientations. For example, in Figure 1, the central woman, whose back is turned toward us, has an anomaly in her right leg. As detailed in Figure 2, the hip to the toes of her foot represents a left leg in orientation (right side of the figure), and there is no normal right leg in the display. Looking at the foot of this leg, we see a front view of a left leg with the inner edge of the foot. However, the lady is being shown from behind, an impossible posture. Careful observation shows that the artist is showing the front view of her left leg in the place of her right leg. In other words, the "lady" has two left legs, one inverted on the body.

In another erotic sculpture (Figure 3), the central "man" appears to be enjoying sex with three women simultaneously, with his knees bent and his legs wrapped around the woman sitting atop him. What is curious is that the leg on the left of the man (also on the left side of the viewer) reveals a foot with its outer edge to the viewer, not the inner edge as should be the case in this position. Moreover, the toes of this foot are turned to the right whereas they should have turned to the left in the present posture. It is clearly a case of the outer side of the right leg being shown in place of the inner side of the left leg. In other words, the man has two right lower legs.

The sculpture shown in Figure 3 has been described as "Kamakala Yantra" [yantra is a mystic diagram with occult powers (170305)]. In this case, the head-down pose is believed to embody the yogic-philosophic symbolism of the unification of the two breaths (Ida and Pingala) in the middle path of the "sushumna" to lead the yogi beyond the phenomenal world (Desai, 1996, pp. 195-196). As shown in the diagram in Desai's book, the middle line of this "Kamakala yantra," representing "sushumna," passes through the 
The "Kamasutra" temples and psychedelic spirituality

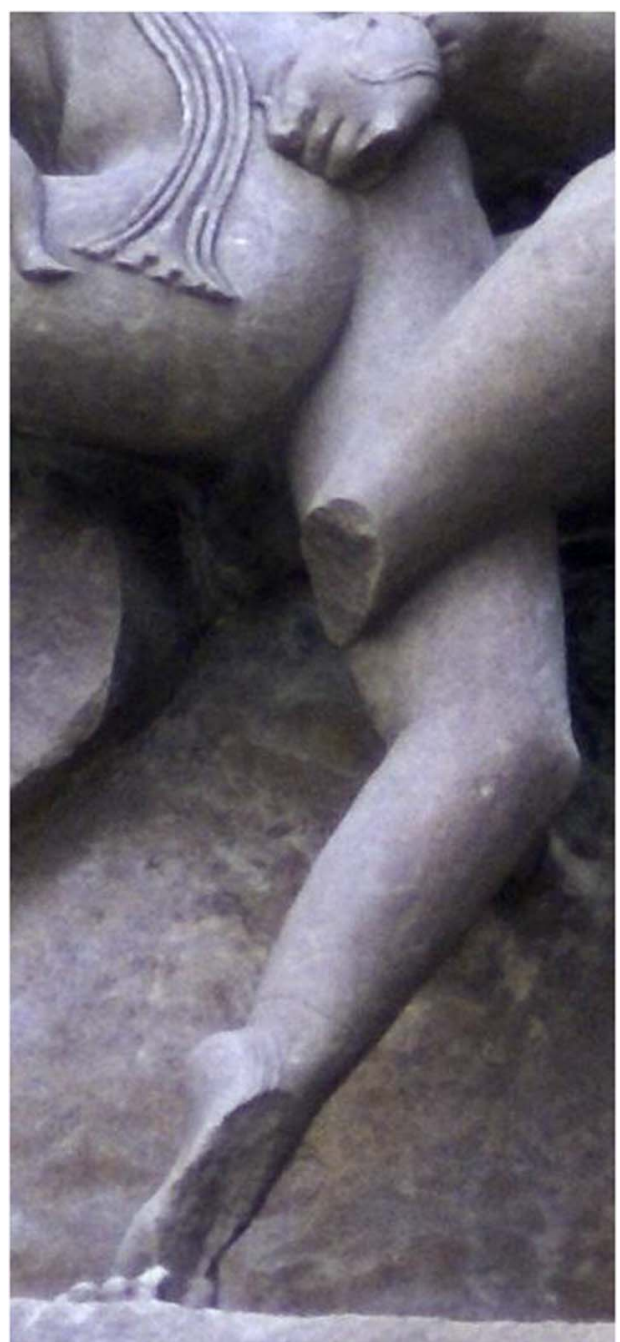

Figure 2. Front of left leg in place of back of right leg. Details of Figure 1

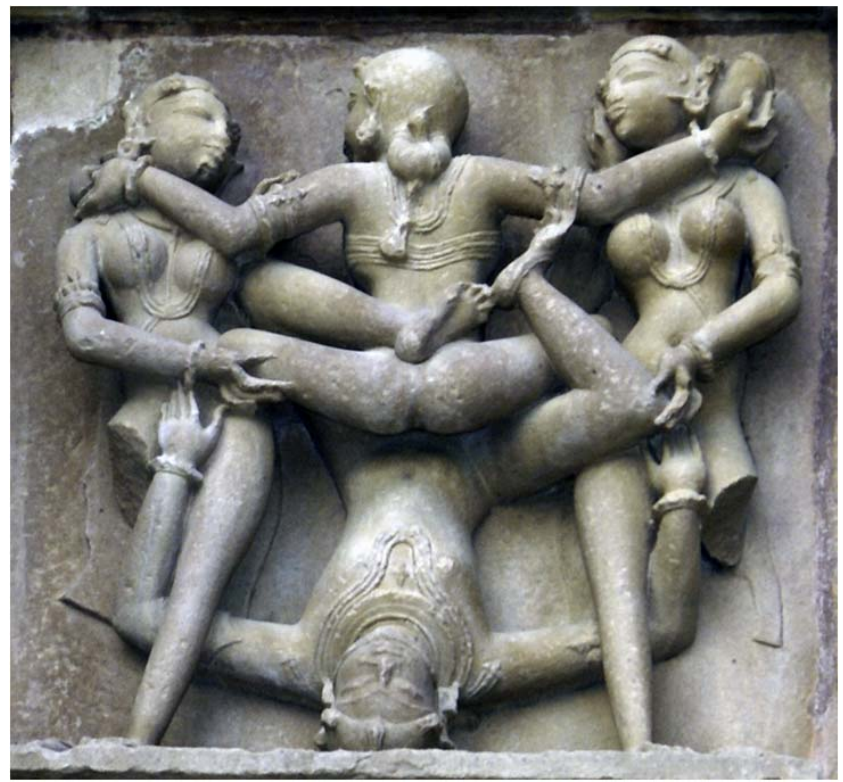

Figure 3. Kandariya Mahadeva Temple, Khajuraho

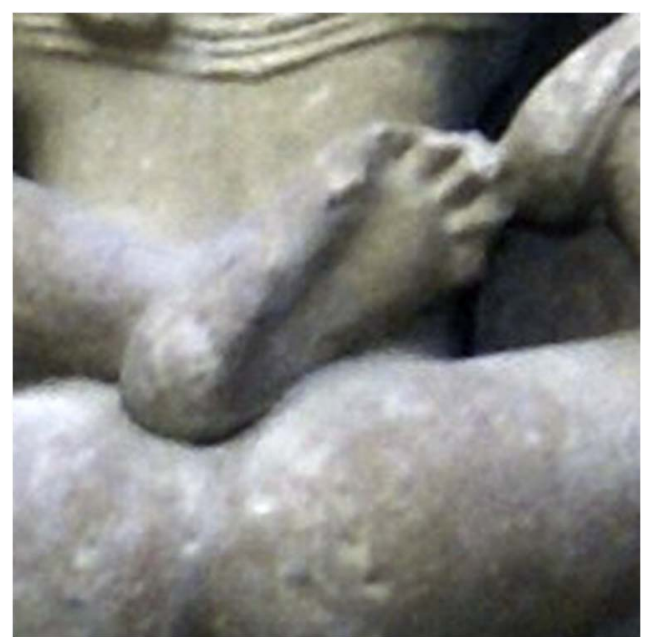

Figure 4. Right foot from behind in place of left foot from the front. Details of Figure 3

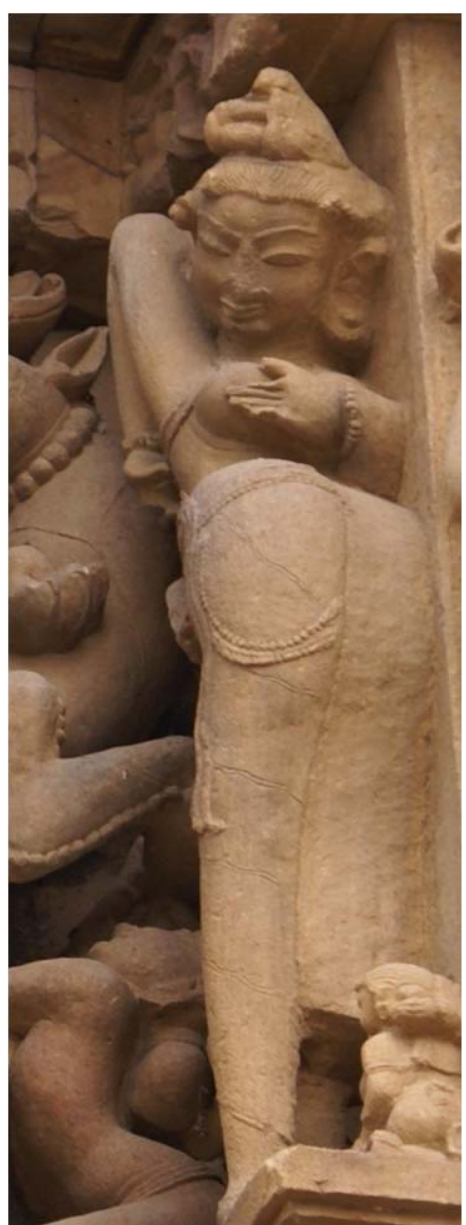

Figure 5. Outer wall of Vamana Deva Temple

heel of the right foot (the inverted foot), although Desai has made no comment about the anatomical aberration, the details of which we have shown in Figure 4.

In Figure 5, a "woman" is shown with her front upper body and face attached to the backside of her legs. The right arm has a strange orientation and the wrist ends in a weird "claw"-like structure. 


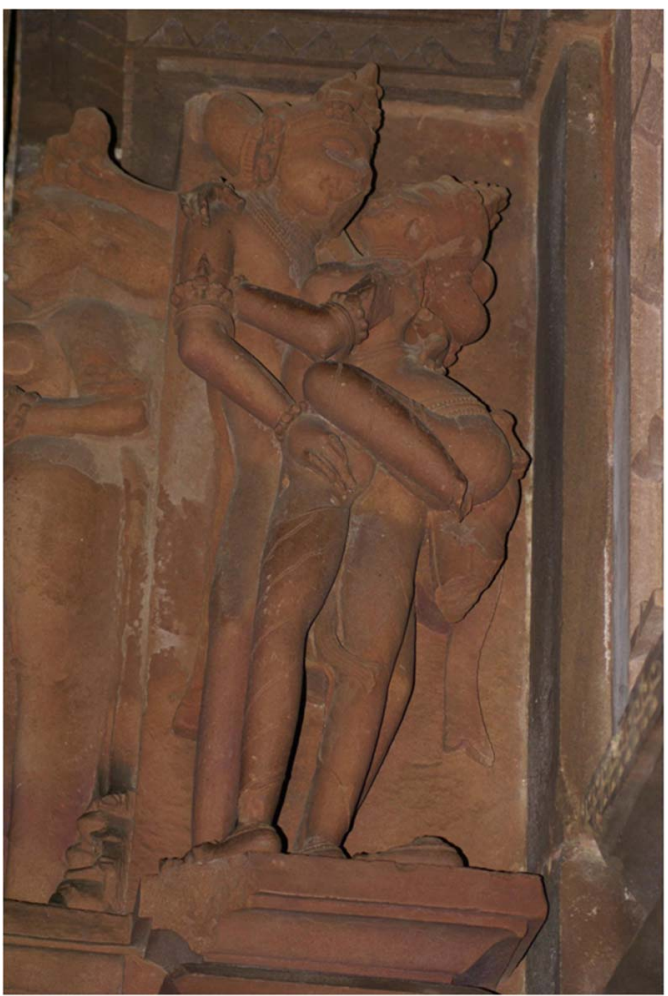

Figure 6. Kandariya Mahadeva Temple, Khajuraho

To give one more example of this weird phenomenon, the "lady" in Figure 6 has two "broken" and two intact legs. If we say that the sculptor is showing two women with one man, then where did the body of the second woman disappear?

In Figure 7, we see a bizarre contrast of the beautiful legs and buttocks of a person (woman?) with two ugly broken

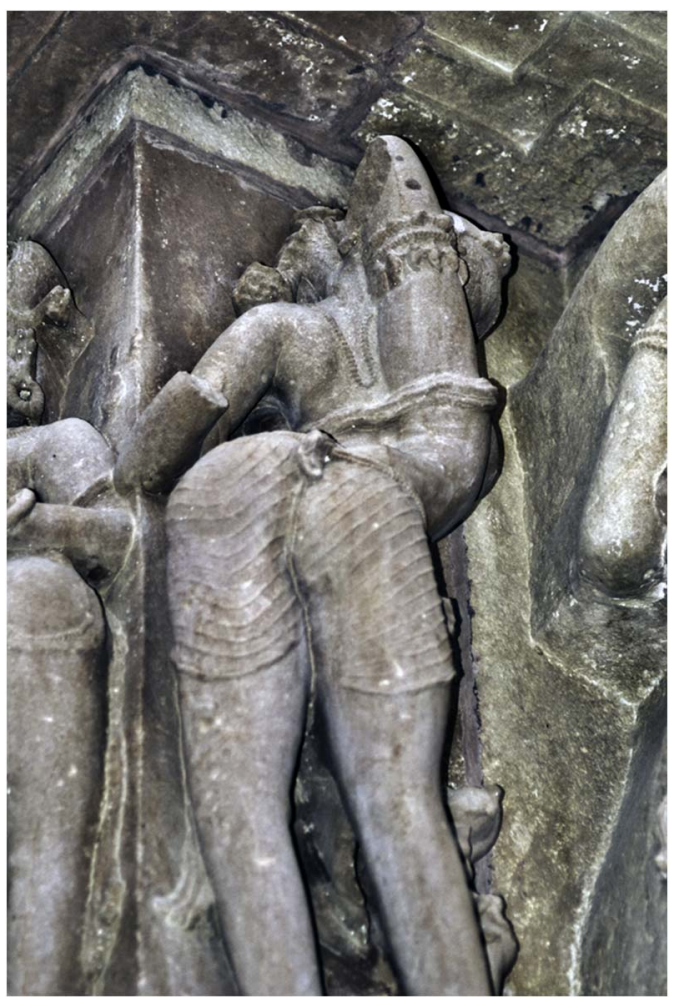

Figure 7. Outer wall of Lakshman Temple arms. The orientation of the arm on the left of the viewer is as if from the front of the body but the lower limbs suggest it is the back that faces the viewer. The other side of the body, on the right side of the viewer, has an enlarged limb where the arm should be, extending up to what appears to be a vandalized upper area. The damaged arms can be easily attributed to vandalism, except in the details of this figure, we see that the "damaged" area of the forearm and the head in the center of the picture appear to be connected to a mushroom clearly placed in the "damaged" area of the face (or the back of the head, whatever our imagination allows us to see; Figures 7 and 8).

Notice the mushroom stem starting from the broken edge of the forearm in Figure 8. The cap of the mushroom is placed on the "damaged area of the face or the back of the head" of the sculpture. The mushroom would not be possible without the deliberate omission of the arm and head, suggesting that the "damage" was intended by the sculptor.

At first look, this art makes us believe that the sculptures are a representation of an exceptionally virile and sexually promiscuous group of humans. A careful examination reveals that these sculptures are not so much intended to depict normal humans and their sexual activities, but rather to encode another message. The weird transposition of the limbs of the figures reflects a dismemberment that has significant precedents in shamanism, Hinduism, and Buddhism as a symbol of spiritual development.

\section{SHAMANIC DISMEMBERMENT}

The dismembered limbs of the figures of Khajuraho can be interpreted with reference to Eliade's (1964) characterization of shamanic dismemberment experiences as variants of the universal theme of mystical death and rebirth. He recounted the initiatory death experience of the Yakut Siberian shaman of being cut to pieces, the head placed to observe the limbs disjointed, the organs removed and consumed by beasts, the flesh scraped away to the bones, and the eyes torn out (paraphrase p. 36). Eliade also described the initiation of the Australian medicine men involving a ritual death during which the spirits removed the initiate's organs and specific bones, perforating the tongue and removing the head. The reconstruction returned the pieces of the body and organs together and often

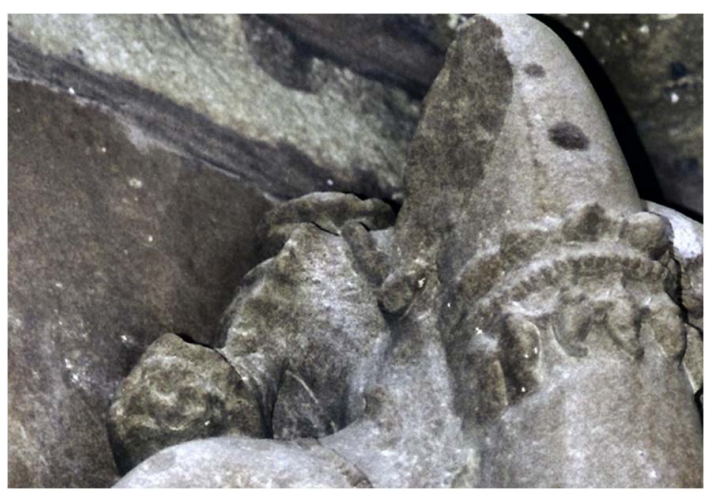

Figure 8. Mushroom in detail of the top part of Figure 7 
involved the insertion of rocks, crystals, or other power objects, as well as animals or mythical beings.

Similar accounts of shamanic dismemberment found across Eurasia, in Australia, Africa, the Americas, and around the world illustrate that it is related to intrinsic aspects of human nature rather than just cultural belief. The experiences may emerge spontaneously, or as a consequence of shamanic initiatory practices such as a vision quest involving prolonged periods of austerities, generally alone in the wilderness, which could last for weeks. The neophyte sought a vision through fasting, prohibitions on sex, and practices designed to induce extreme pain, temperature extremes, and sleep deprivation, accompanied by ritual activities to call the spirits.

\section{Dismemberment as psychological transformation}

The shaman's death-and-rebirth experiences represent processes of psychological transformation that occurs as a result of overwhelming stress and the intrusion of unassimilated neural structures (Walsh, 1990). The recurrent phenomena of experiencing personal death and dismemberment, followed by a rebirth, are representations of deep archetypal processes. Walsh proposes that these transformative processes occur as a result of the inability of the psyche to maintain an integrated understanding of self, with the underlying conflicts leading to a destructuring of egoic consciousness. The inability of the reigning psychological structures to manage the conflicts results in a collapse of the psyche, including personal identity and perhaps even beliefs, habits, and conditioning. This is experienced as personal death, reflecting the destruction of one identity, followed by a rebirth experience in development of a new identity. Laughlin, McManus, and d'Aquili (1992) suggested that this collapse of internal structures is experienced as dismemberment, with "autosymbolic images" of dismemberment representing the breakdown of the psyche.

The threatening images that appear as attacking beings are symbols of the shadow, which involves the disowned aspects of the self and the psyche that are repressed because they are considered to be evil. The breakdown of the ego allows for these structures to emerge into consciousness, perceived in symbolic forms as threatening entities. The disowned structures are conceptualized in spiritual terms and externalized because the locus of intentionality for these impulses is dissociated from the conscious ego.

The collapse of the psyche sets the stage for activation of a psychological reorganization guided by an archetypal drive toward holism, structured by the cultural beliefs. Walsh (1990) suggested that the spontaneously occurring spiritual entities become familiar and associated with positive symbols with affect, losing their terrifying nature as the shaman develops the ego strength to assimilate these structures. These psychological transformations lead the shaman to transcendence at a new level, experienced as a magical flight that symbolizes transformations of structures of consciousness (Winkelman, 2010).

\section{Dismemberment in Hinduism and Buddhism}

Eliade also discussed how these dismemberment experiences are utilized for dramatic functions in rituals. The
Indian fakir engaged the illusions of dismemberment in conjunction with the rope performance that made a rope appear to arise in the sky. The fakir's assistant climbed the rope and disappears into the sky, followed by his limbs, head, and other body parts falling to the ground. The performance of this illusion is reported for Buddha. Eliade (1964, citing Buddhacarita, vv 1551ff) tells us that Buddha "to convince his relatives of his spiritual capacities and prepare them for conversion, he rose into the air, cut his body to pieces, let his head and limbs fall to the ground, then rejoined them together again" (p. 428). Eliade links this rope ascent and dismemberment to the universal shamanic traditions of dismemberment and celestial soul flight, which he also found recorded in the archaic pre-Buddhist traditions of India and Tibet.

Thus, shamanic, Hindu, and Buddhist traditions provide a basis for interpreting the dismembered limbs depicted in the sculptures of Khajuraho as symbols of spiritual transformation and growth and clue us to look for additional spiritual messages, including the entheogenic mushrooms.

\section{MUSHROOMS IN THE VISHWANATH TEMPLE, KHAJURAHO}

The stairs of a typical Khajuraho Temple lead the visitor to an entrance porch, which connects to a hall, which may in turn open into a bigger hall. Depending on the size of a temple, the number of halls in temples varies. For example, Lakshmana Temple has one smaller hall and one bigger hall (hall with transepts; Desai, 1996, p. 100).

The vestibule is a small enclosed area in front of the sanctum sanctorum. The sanctum is a small, windowless chamber, over which the highest part of the temple, the tower, is constructed. In some temples, devotees can make a circumambulatory course around the sanctum. In others, they come up to the sanctum, pay obeisance, and return. In no case are the devotees allowed to enter the sanctum that is the home of the divinity. Since Khajuraho Temples are not under active worship, this rule does not apply and the tourists can enter the sanctum.

The most important structures of the temple are contained in the tower: the sanctum, Amalaka (a huge segmented wheel), and Kalasha (a huge pot-like structure), the latter two built on top of the tower that rises over the sanctum. The vestibule, the small enclosed area between the "halls" and the "sanctum" of the temple, contains the threshold to the sanctum. It is here that we find strategically placed mushroom sculptures in many Khajuraho Temples.

In Figure 9, we see the prominent placement of a mushroom at the threshold of the sanctum of the Vishwanath Temple at Khajuraho.

Figures 9 and 10 reveal a mushroom more than a foot in height, carved into solid rock at the threshold of the temple sanctum. The stone used for the execution of this sculpture is red sandstone. There is a special design in the middle of the stem that could represent the remains of the veil (annulus) from the mushroom cap, expanded in Figure 11.

The placement of the mushroom in front of the sanctum, the threshold, which allows entry into the sanctum, has significance as it is the access to the innermost part of the temple. 


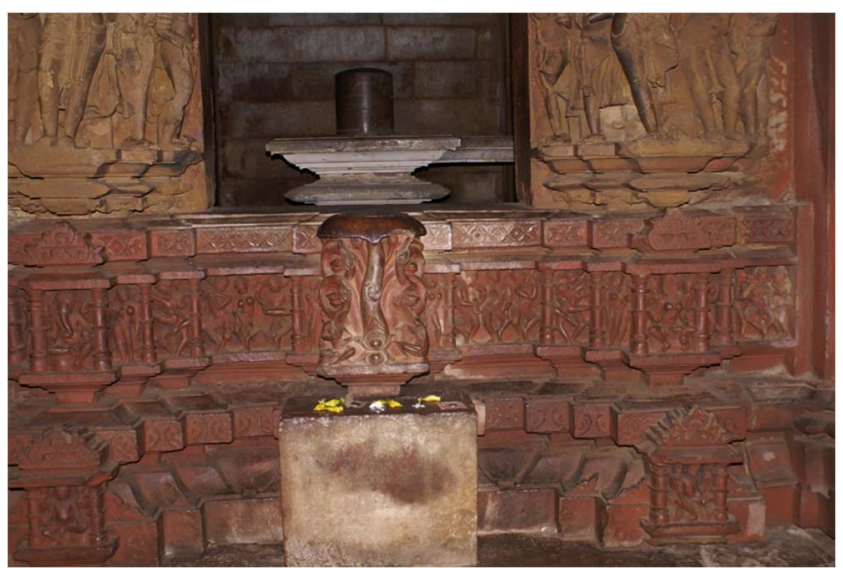

Figure 9. Mushroom sculpture in the vestibule, at the sanctum threshold of Vishwanath Temple, Khajuraho

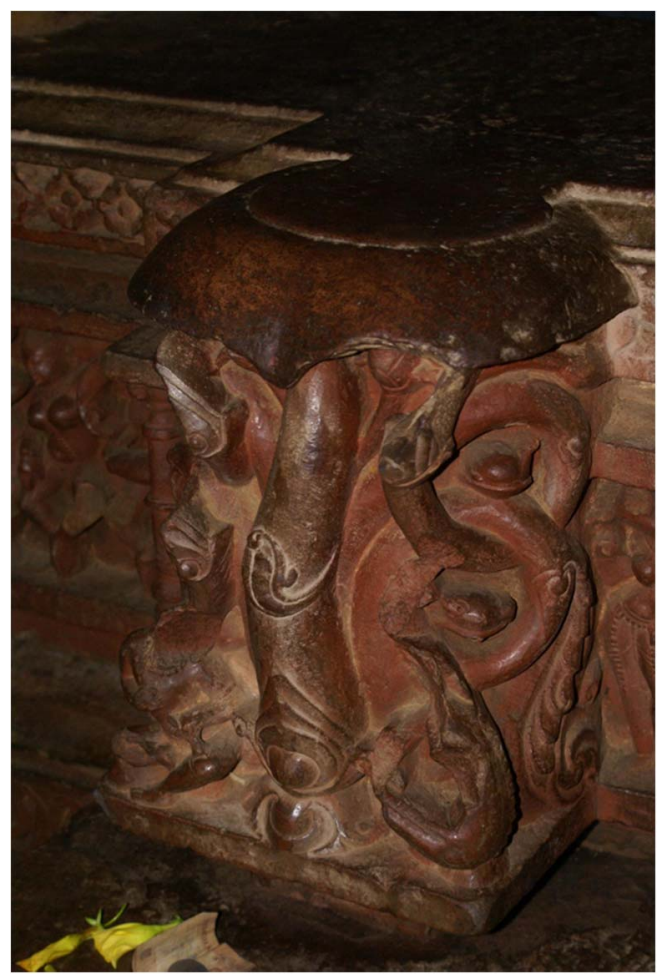

Figure 10. Mushroom at the sanctum threshold of the Vishwanath Temple

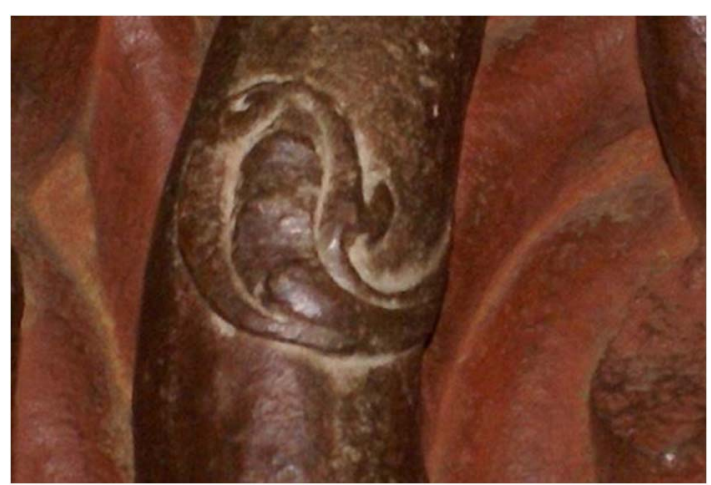

Figure 11. Possible representation of the remains of the veil on the mushroom
Some authors call this area "Sandhi-Kshetra," which means "junction," where the sanctum of the temple and its hall(s) meet. The hall represents the phenomenal world and it is meant for the devotees. The sanctum represents the transcendental world and it is the home of the divinity (Desai, 2007).

Therefore, the presence of a mushroom sculpture at the junction of the phenomenal and transcendental worlds is highly significant. This sculpture in the vestibule of the temple is joined to the threshold of the sanctum in such a way that one cannot enter the sanctum without stepping on the head of the sacred mushroom. The top of the cap of the mushroom merges seamlessly with the floor of the sanctum, making the mushroom the rudiment from which the sanctum floor begins, as illustrated in Figure 12.

Not only the top of the cap of the sacred mushroom stepping stone merges seamlessly with the floor of the sanctum, we must stand on it if want to enter the sanctum. After climbing the pedestal on which mushroom sculpture stands, we can put our foot only upon the "head" of the mushroom as the stone around it has been carefully shaped into narrow steps on which the foot will not fit. The unerring message of this construction is that one and only way to the sanctum goes through the sacred mushroom, the "stepping stone" to spirituality.

\section{Mushrooms at other sancta of Khajuraho}

The mushroom sculpture is systematically repeated at the sancta of several temples in Khajuraho. Figures 13 and 14 show the threshold of Jagdambi Temple.

Similarly, Figure 15 gives the top view of the sanctum threshold of Parshwanath Temple, Khajuraho. Figure 16 gives the front view of this mushroom and Figure 17 shows the mushroom threshold of the Chitragupta Temple, Khajuraho.

Mushrooms are depicted all over the temples. For example, in Figure 18, an eight-handed Elephant God is depicted holding a mushroom in one of his hands on the right side of the picture.

\section{A. MUSCARIA AS A SACRAMENT}

The central presence of mushroom representations in the Khajuraho Temples indicates that they are significant and

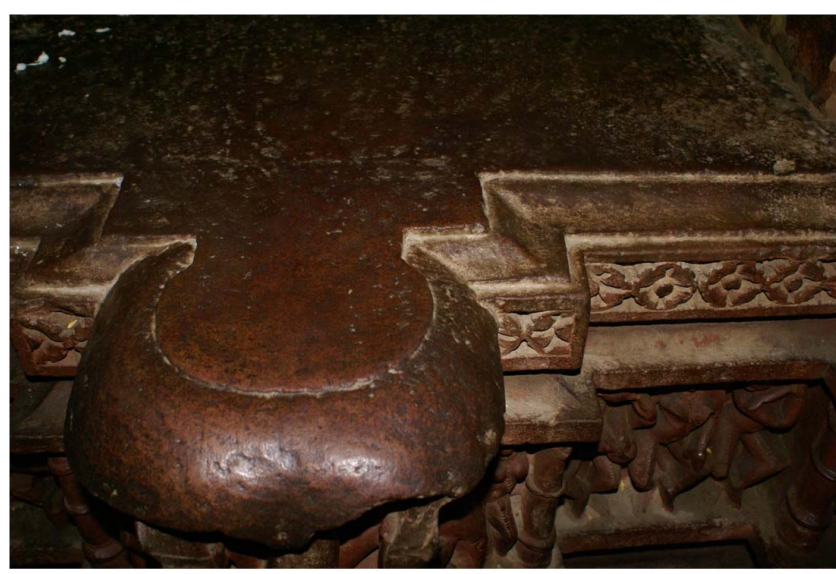

Figure 12. Top view of mushroom at the sanctum threshold of Vishwanath Temple 


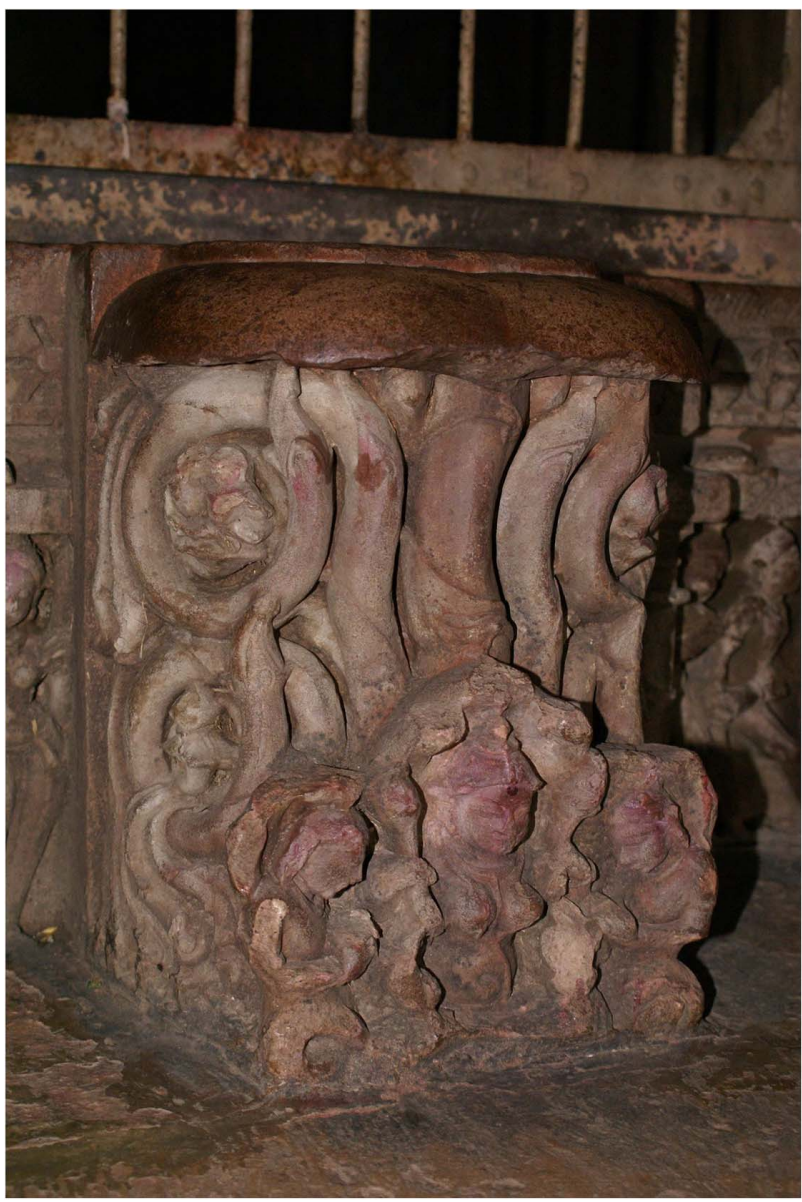

Figure 13. Mushroom sculpture at the sanctum threshold of Jagdambi Temple, Khajuraho

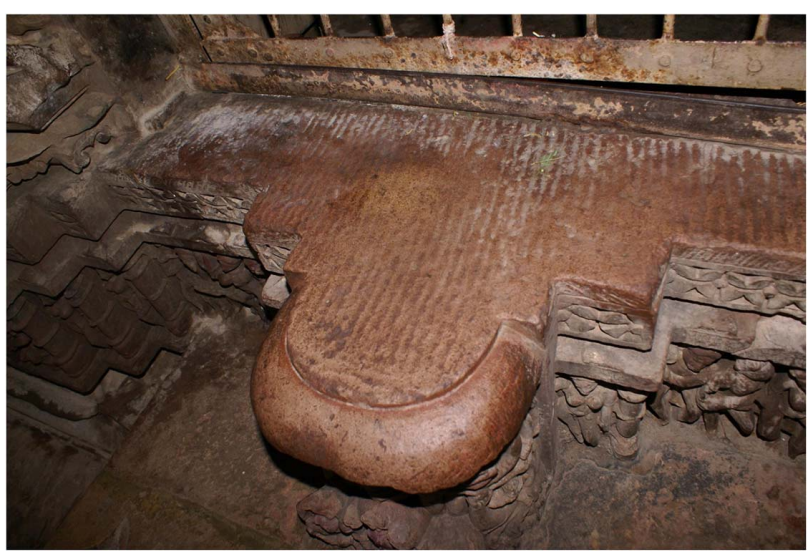

Figure 14. Top view of the mushroom in Figure 13 (Jagdambi Temple, Khajuraho)

should be identified. Scholarly examinations of the literature of the Hindu traditions have produced various hypotheses regarding the identity of sacred mushrooms in their spiritual traditions (see "Soma and Haoma: Ayahuasca Analogues from the Late Bronze Age" by Matthew Clark in this special issue Psychedelics in the past). The ancient Aryans who invaded India around 3,500 years ago brought with them a highly esteemed sacrament referred to as soma. Wasson (1968) proposed that the ancient Vedic soma was a psychedelic

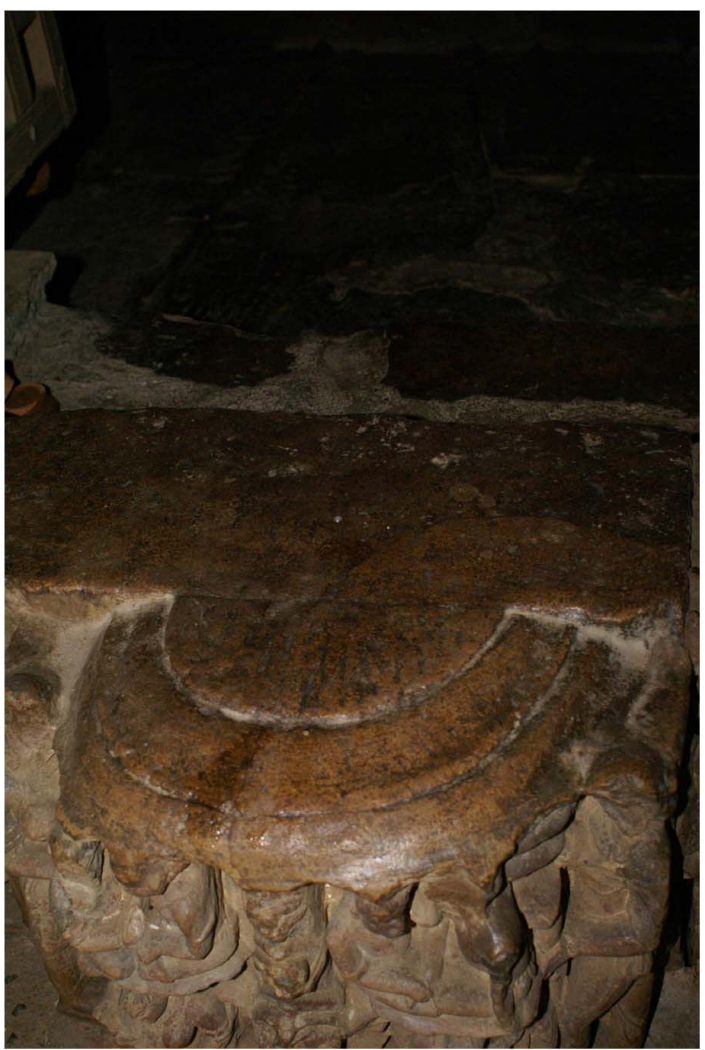

Figure 15. Top view of the mushroom sculpture at the sanctum threshold of Parshwanath Temple, Khajuraho

mushroom [A. muscaria (L. ex. Fr.) Persoon ex W. J. Hooker], an idea with revolutionary implications that basic principles of Hindu religion derived from psychoactive plants that stimulated humanity's primordial religious impulses through the entheogenic practices related to shamanism.

Wasson (1968) proposed that religious use of $A$. muscaria began at least 10,000 years ago, sometime after the last Ice Age, in the northern Eurasian forest belt. The Aryan practices had roots in this ancient ritual use of $A$. muscaria among the northern peoples of Europe. This antiquity is substantiated by its use across the expansion of northern Asia and Europe and with a common linguistic root among diverse unrelated Siberian, Asian, and European cultures (Schurr, 1995). The expansion of $A$. muscaria use across the northern expansion of Eurasia undoubtedly followed the retreat of the glaciers around 10,000 years ago, which opens up habitat for $A$. muscaria in its symbiotic relationship with Betula spp. (birch) and Pinus spp. (pine trees).

Further evidence for the antiquity of $A$. muscaria use is found in presence among Native Americans of shamanistic practices involving $A$. muscaria that parallel those of the Siberian cultures, suggesting that mushroom traditions accompanied the Paleo-Indian immigrants from Asia into the Americas (Rätsch, 2005). Ethnographic studies inform us that the traditional ingestion of $A$. muscaria always involved shamanic practices, although there are more modern cases of non-ritual individual use. This shamanic context of A. muscaria use was part of a broader tendency to use ritual to produce alterations of consciousness experienced as a travel to and entry within the spirit world. The widespread association of the A. muscaria with reindeer reflects the 


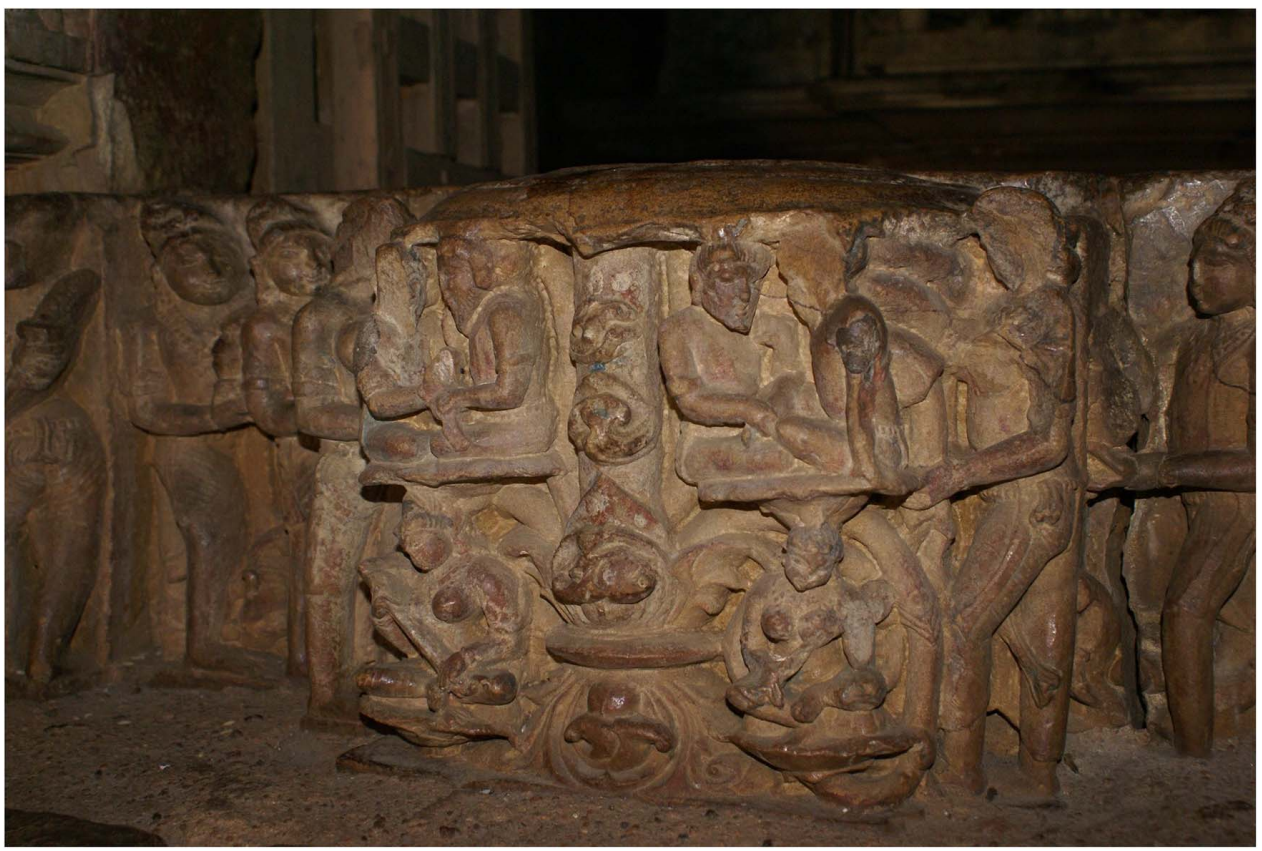

Figure 16. Front view of the mushroom sculpture at the sanctum threshold, Parshwanath Temple, Khajuraho

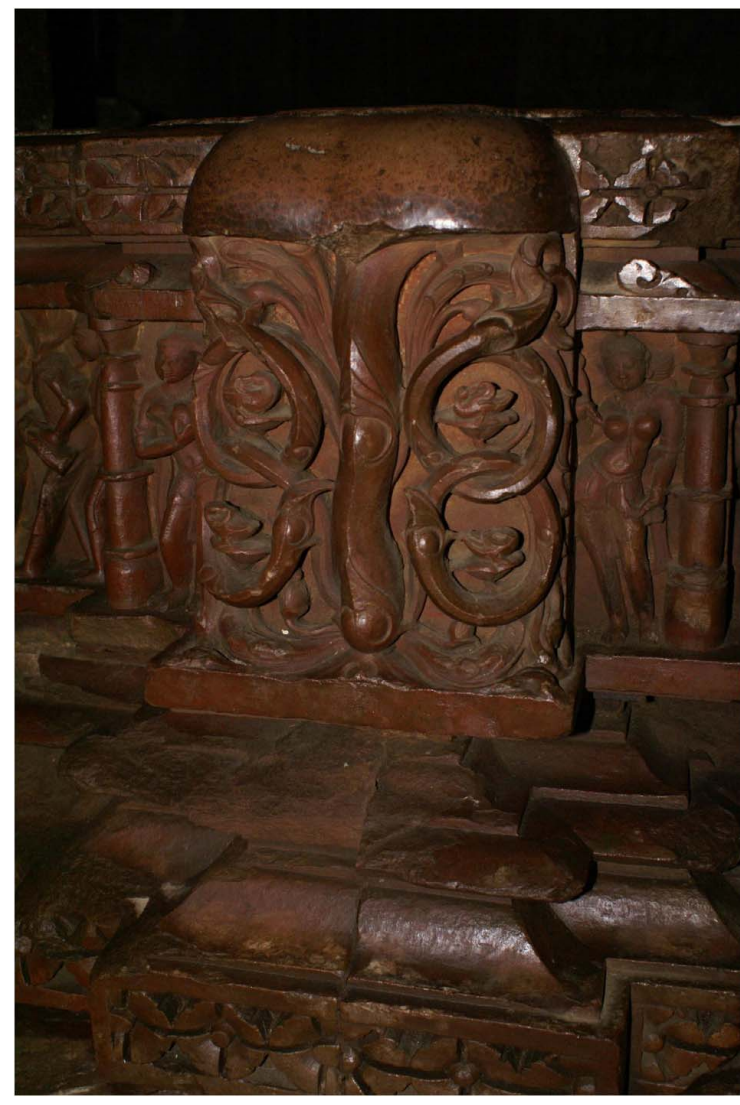

Figure 17. Mushroom sculpture at the sanctum threshold of Chitragupta Temple, Khajuraho

animal's practice of consuming the mushrooms, and may reflect the origins of human knowledge regarding the mushroom's properties. The effects of $A$. muscaria derive from its constituents, muscazone and ibotenic acid, as well as muscimol in dried samples (Rätsch, 2005). A. muscaria may be

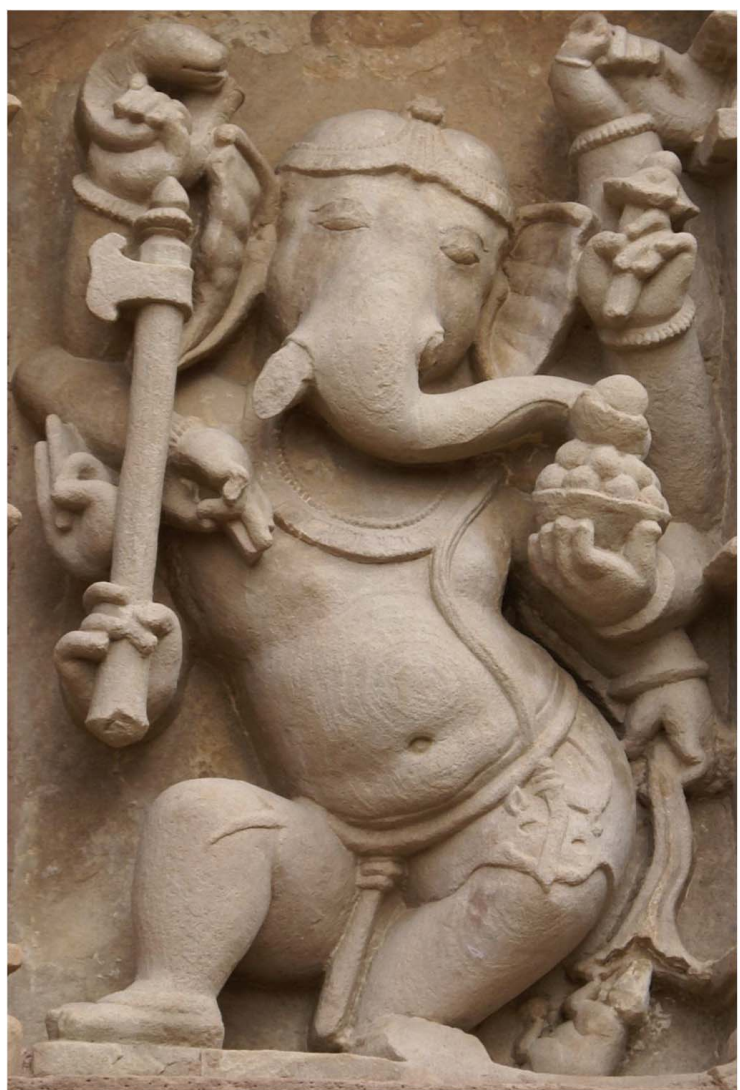

Figure 18. Elephant God holding a mushroom. Outer walls of Lakshman Temple, Khajuraho

mixed with other plants that enhance its psychedelic effects: bilberry (Vaccinum uliginosum) and fireweed (Epilobium angustifolium; Saar, 1991).

Data on the use of $A$. muscaria among groups in Siberia and North-East Asia (e.g., the Chukchi, Koryak, Itelmen, 
Russians, Chuvanians, Yukagir, and Events; Saar, 1991; also see Dannaway, 2009 for Asian practices) show that diverse ethnic groups of Siberia shared the idea of $A$. muscaria as a supernatural being. These diverse groups believe that the human world is intertwined with the world of spirits and that A. muscaria can be used to influence the course of events in human life. Shamans use $A$. muscaria to leave their body to contact the spirits and get information from them. Often the shaman falls in a deep sleep after consuming A. muscaria and only starts influencing the supranormal world after they have woken up. During the deep sleep, the spirits of $A$. muscaria take control of the shaman's spirit, and use him as a means to disseminate information to the listeners, singing to them through the shaman. In many songs, the shamans appeal to $A$. muscaria to be a mediator to contact the superior beings.

Saar goes on to explain that the Siberian tribes use A. muscaria also as a psychostimulant to get inspiration to recite heroic epic songs embedded in folk-lore. The A. muscaria is believed to give the singers the strength and ability to continue singing throughout the night in a loud voice, consistent with the alleged uses in ancient Vedic practices. They believe that using A. muscaria enhances memory, which also leads to recall of even the long-forgotten songs. A. muscaria consumption is also associated with an extraordinary increase in physical stamina. Saar gives examples of instances when people could walk for hours through the snow, do strenuous physical work for whole day, jog for kilometers, and hunt for long hours, without getting tired. Therefore, A. muscaria seems to reduce physical, psychic, and psychological limitations in conditions of extensive exertion.

There are unusual and significant characteristics across Siberia in the ritualized use of $A$. muscaria in practices associated with the drinking of the urine of both human users of the mushroom and the deer that are intoxicated on them (see Crowley, 2016). This practice reflects the concentrated presence of the active ingredients in the urine of those who consume it, including both most of the original muscimol and the additional dosage of muscimol resulting from the metabolization of the ibotenic acid. This urine drinking is one of Wasson's arguments for the identity of soma as A. muscaria. In a passage of the Mahabharata too, there is a discussion about the consumption of the urine of God Krishna (an incarnation of Vishnu), disguised as a hunter, with the liquid identified as amrita (soma). Since ethnographic and historical knowledge of traditions of entheogenic urine drinking is limited to A. muscaria, it seems to indisputably establish its identity as soma.

\section{A. muscaria in India}

Based on correspondences with the descriptions provided in the Rig Veda, Wasson $(1968,1971)$ argued that the soma that the Aryans brought with them to the Indus Valley was A. muscaria. It was this fungus that had been deified as their God called Soma, which also referred to the plant and the juice of that plant that was consumed as a sacrament. Among Wasson's arguments for the plant identity of soma being A. muscaria was the lack of mention of normal plant parts such as leaves, trunk, or roots, while simultaneously making references to features consistent with the color, form shape, etc., of the mushroom (see below). The references were metaphoric rather than direct because an explicit word for mushroom is alleged to not exist in Sanskrit (Crowley, 2015, 2016). Although a word may have existed, it is speculated that it was deliberately excluded from the language because as a sacrament it was hidden from common knowledge (Crowley, 2016). Wasson proposed that the alleged metaphoric language of the poets of the Rig Veda was literal descriptions of the various features of the mushroom, providing a number of major correspondences between the mushroom features and descriptions of soma found in Vedic texts. Wasson related the descriptions of soma in the Rig Veda to the environment, growth stages, features of $A$. muscaria, and the various features of this plant to the descriptions of the soma Gods, especially Agni (see below for discussion). Wasson noted passages in the Vedic scriptures paralleling the widespread Siberian practice of consuming the urine of reindeer (or human) who drink A. muscaria. The metabolism of the mushroom ingredients transforms toxins, increasing the concentrations the most active ingredients of the mushroom. Such connections make sense of why the stag is prominently mentioned in the scriptures in relationship to the pissing out and drinking of soma.

While Wasson proposed that the mushroom A. muscaria was soma, he noted the difficulty in access to a plant that grows in mountain regions and cannot be cultivated. Consequently, it was necessary to develop substitutes because of the limited supply of the mushroom, which normally grows in underground symbiosis with pine, fir, and birch trees and therefore does not lend itself to cultivation. With the scarcity of A. muscaria, coupled with the presence of the highly similar Psilocybe cubensis in tropical latitudes, the later became assimilated to and identified with the classic fungal soma (Crowley, 2016). The subsequent identification is also provided in later Vedic commentaries of soma as having a blue throat and associated with cowherds, features that attest to the identification of soma as $P$. cubensis, which grows through cow dung.

There also have been many alternative plants proposed for soma (see Merlin, 2018; Crowley, 2016; and Clark, here for reviews). These include: Ephedra (Bowman, 1970; Mahdihassan, 1983; Merlin, 2013), Perganum harmala (Flattery \& Schwartz, 1989), Cannabis (Bennett, 2010; Merlin, 2003), P. cubensis (Earle) Singer (McKenna, 1993), and other species (Crowley, 2016). Merlin (2018) reviews evidence suggesting that the original source was an Indo-Iranian plant combination of Ephedra, Cannabis, and opium, and Clark (this volume) has presented evidence of other plant combinations as soma candidates.

But was $A$. muscaria the original soma? The lack of a picture of $A$. muscaria in the Rig Veda texts has made a definitive identification of the sacrament thus far inconclusive. We propose that a more definitive identification might be provided by an analysis of the features of sculptures of Khajuraho, combined with an analysis of $A$. muscaria features and the details in the sacred texts. In the following sections, we provide a review of: observable botanical features of $A$. muscaria and $P$. cubensis, the relationship of the A. muscaria features with the insignia of religious deities, a comparison of mushrooms depicted in the Khajuraho Temples with the mushroom botanical descriptions, and an 
analysis of Vishnu names and their meanings in relationship to the mushroom features to support the argument that the original soma was $A$. muscaria.

\section{A. MUSCARIA AND P. CUBENSIS FEATURES}

A. muscaria, a beautiful and fascinating organism, is shown in Figure 19. Usually found in the vicinity of birch, pine, spruce, and fir trees with which it has a symbiotic

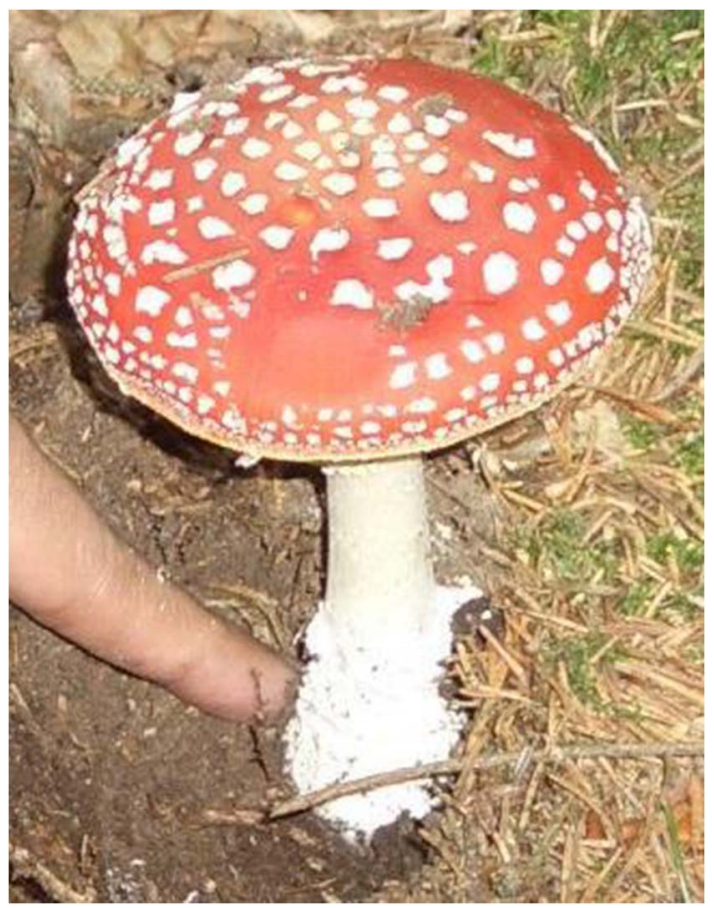

Figure 19. A. muscaria relationship, it presents a distinctive riot of red in the otherwise monotonous background of the forest floor. Flaming orange, vermillion red, and ruddy rust are common colors of its cap. Some larger specimens of the cap might attain to a diameter of one foot. With white spots on its glowing red surface, the iconic mushroom cap has been frequently compared to a diamond-studded tiara.

\section{Growth stages of $A$. muscaria}

A diversity of forms of $A$. muscaria is manifested in the changes that it undergoes as it passes through its various growth stages and takes on several intriguing forms of its fruiting body. Some of its parts adopt such curious shapes that it is difficult to believe they belong to a mushroom.

The forms of A. muscaria (Figure 20) are diverse as a fish, a bone, a chicken leg, a hatchet, the back of a tortoise, a twisted elephant trunk, a flower, a lotus, the disk of the sun, an umbrella, a cap, a water pot, a drinking bowl, fish gills, fish scales, a beautiful wheel, a female breast, a male penis, hair or ear decorations, a mace, etc. Sometimes, the mushroom can also appear to be a shapeless chunk of meat, a formless piece of vegetable, etc. At present, all these forms are interesting because the words associated with them are either directly related to the names of God Vishnu in Sanskrit or are indirectly related to him through the synonyms of his names. Some of these shapes can be seen in Figure 20.

The parallels between $A$. muscaria shapes and names of God Vishnu provide one form of evidence for the idea that the mushroom attributes are encoded in the names of a Deity. We further find correspondences of the basic features of $A$. muscaria with features of Vishnu. The icons of God Vishnu parallel the various forms and growth stages of the mushroom as it will be clear from the following discussion.

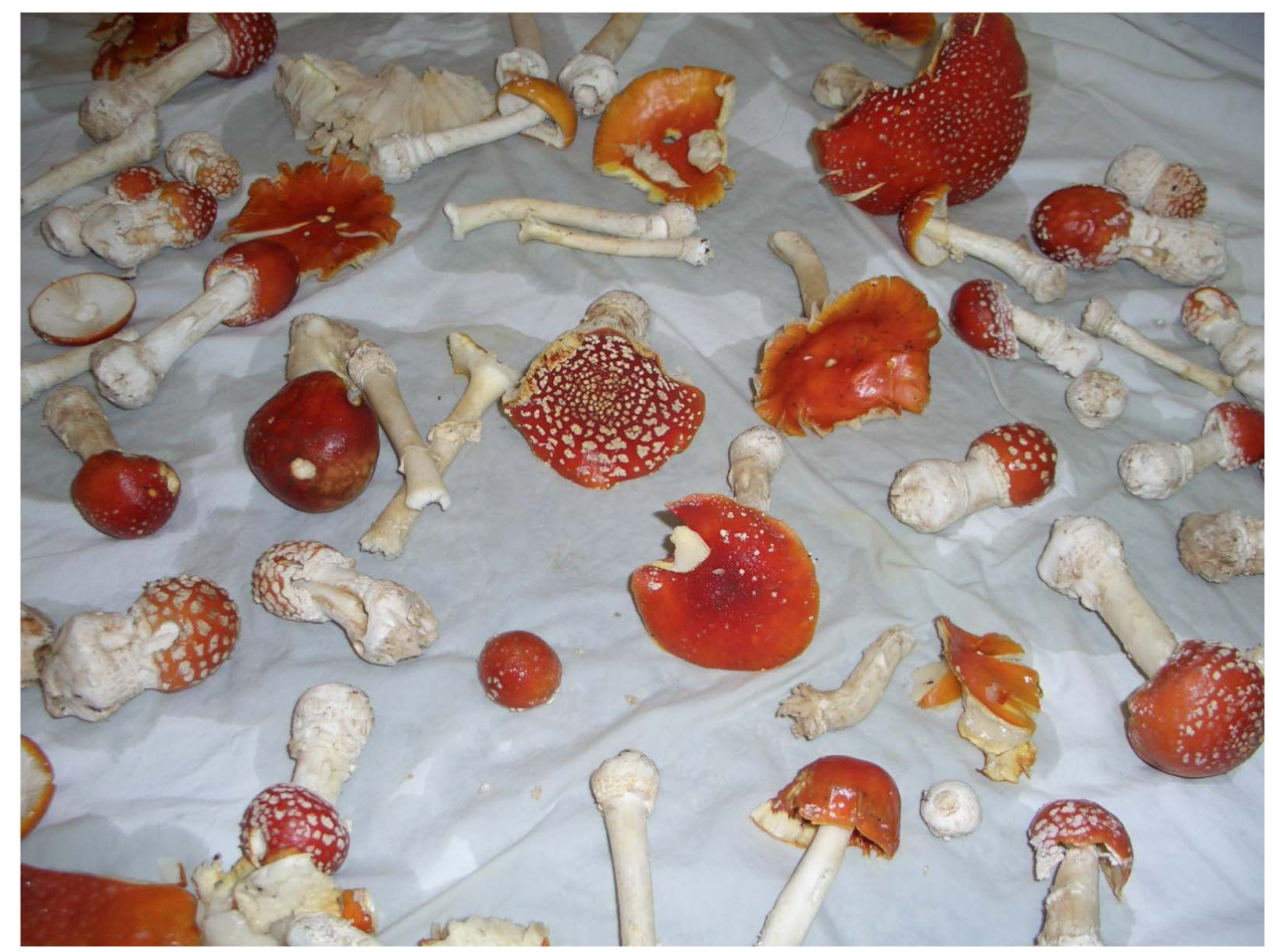

Figure 20. Diverse forms of $A$. muscaria 
Krishna, the Buddha, and the Jain prophets also possess similar icons, especially the wheel, and synonyms of their names are included in the inventory of Vishnu names [Krishna is Vishnu (55154) and Jina (79313) is Vishnu, Buddha, and the chief saint of Jainas]. Some people believe all these Gods/prophets to be the incarnations of God Vishnu, who is first mentioned in the Rig Veda. Therefore, if Vishnu's icons are connected with A. muscaria, it implies that other Hindu Gods and Goddesses, as well as Buddhist and Jain prophets and deities, are also related to the mushroom.

A. muscaria begins its visible life as a tiny "egg" (Figure 21), which can look like the Buddha or the Mahaveera Head, an icon of enlightenment (Figure 22).

The mushroom soon enlarges to become a "figure 8 " as illustrated in Figure 23. In Figure 24, we see the cross section of a very young mushroom, which can also resemble a broader kind of "figure 8."

The mushroom in Figure 24 is the unopened mushroom, cut in half, before the cap and the bulb separate and the stipe becomes visible. We left the two halves of the mushroom

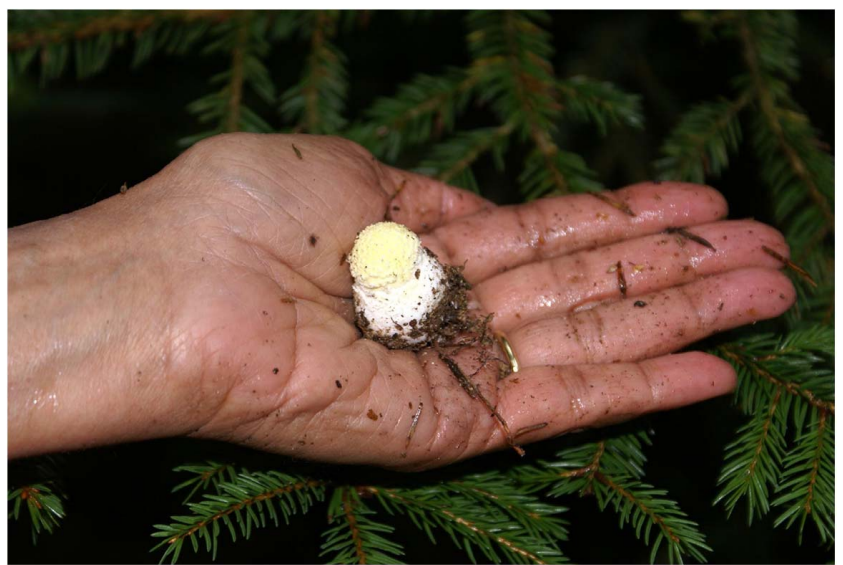

Figure 21. A very young stage of $A$. muscaria

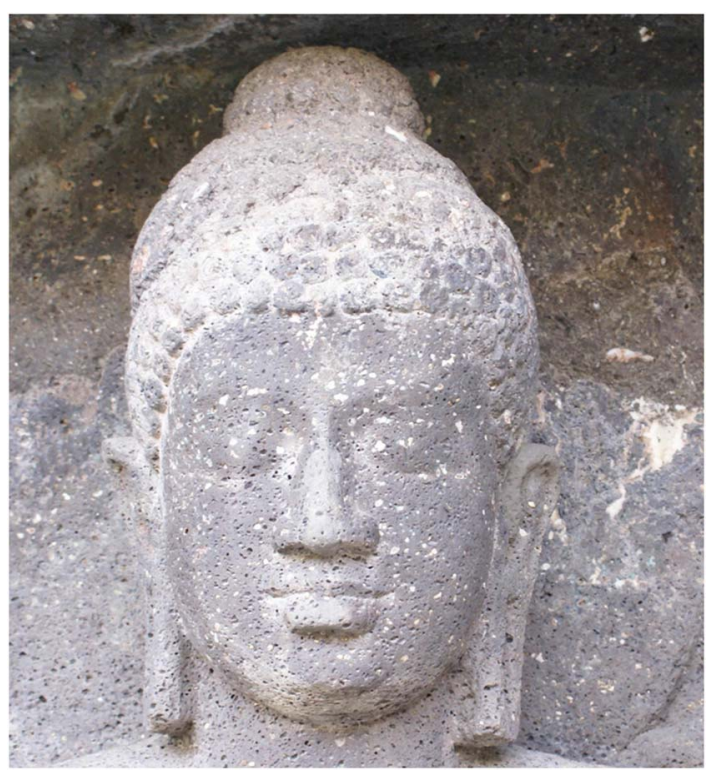

Figure 22. The Buddha head in Ajanta, Cave 26

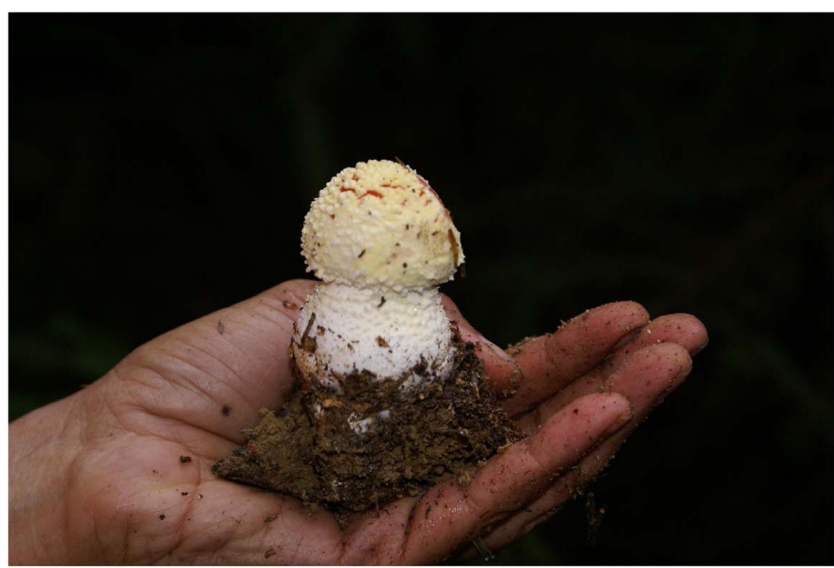

Figure 23. "Figure 8" stage of A. muscaria

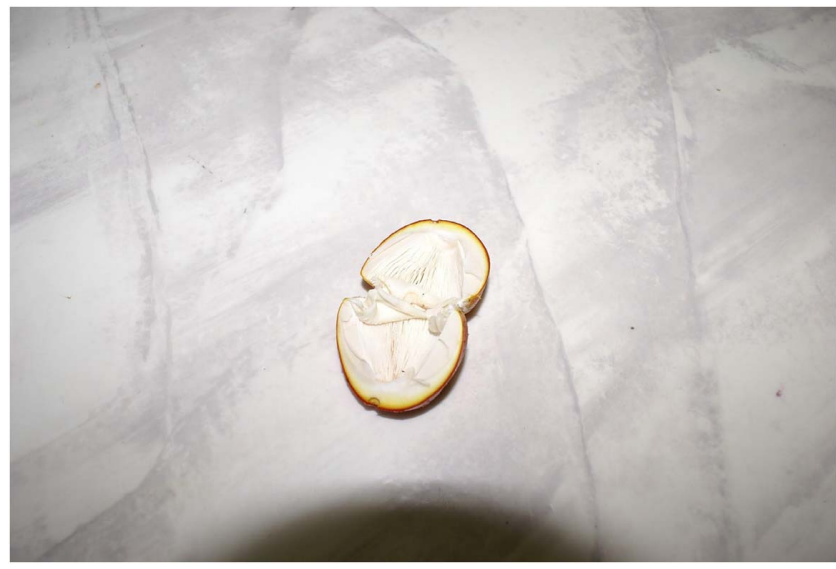

Figure 24. A cross-section of the unopened cap of A. muscaria

joined together at the base, which created an interesting "figure 8."

We propose that the "figure 8" encoded in a number of statues that appear to be damaged actually encodes this phase of A. muscaria growth. The "figure 8" stage, as depicted in Figure 23, and its vertical/horizontal sections appear to be encoded as breasts, testicles, and broken arms and legs of the temple sculptures. Sometimes, a "figure 8" is sculpted in place of the head of a statue. In other examples, a "figure 8" is created through an artistically chiseled knee and thigh, or the knee and elbow of a sitting statue, as we discuss below (see Figures 35-41). In Figures 10 and 17, two serpentine "figure $8 \mathrm{~s}$ " are depicted on both sides of the stem of the mushroom.

In the next growth stage of the mushroom, the "figure 8" elongates and first becomes a short, and then a long dumbbell as shown in Figure 25. This short dumbbell shape (or the earlier "figure 8" shape) may be represented in the idea of the Buddhist dorje, or God Shiva's drum, and the longer form could have led to the conception of Vishnu's mace, which is one of his four important insignia.

Finally, when the cap of the mushroom opens, it has a typical serrated edge and resembles a "wheel" (Figure 26).

The gills of the mushroom (Figure 27), where the stipe is attached to the cap, provide a clear icon of the wheel that is widely found in Hindu/Buddhist/Jain depictions. 


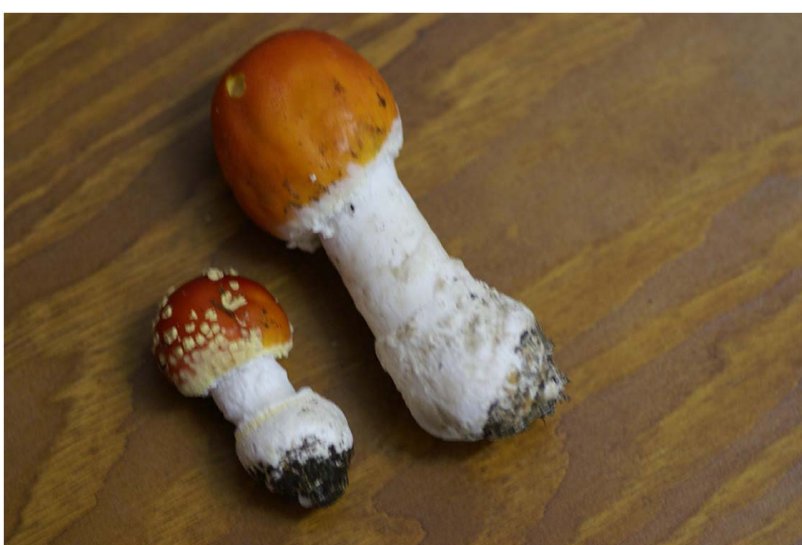

Figure 25. A short and a long dumbbell stage of $A$. muscaria

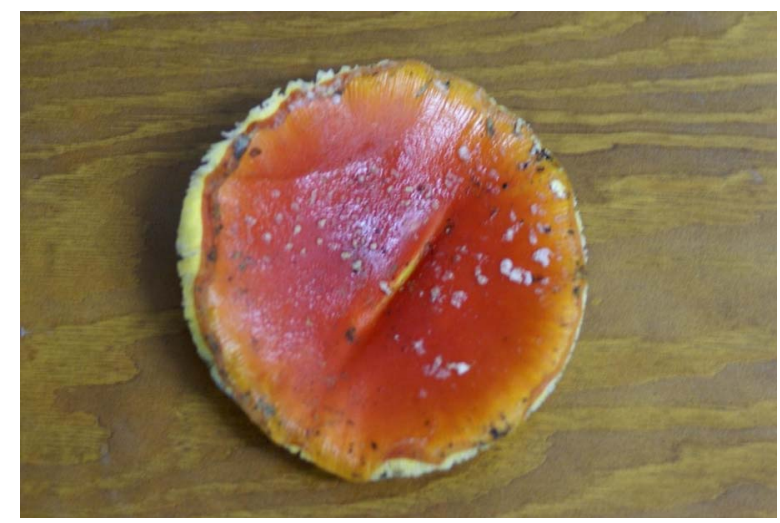

Figure 26. A. muscaria cap

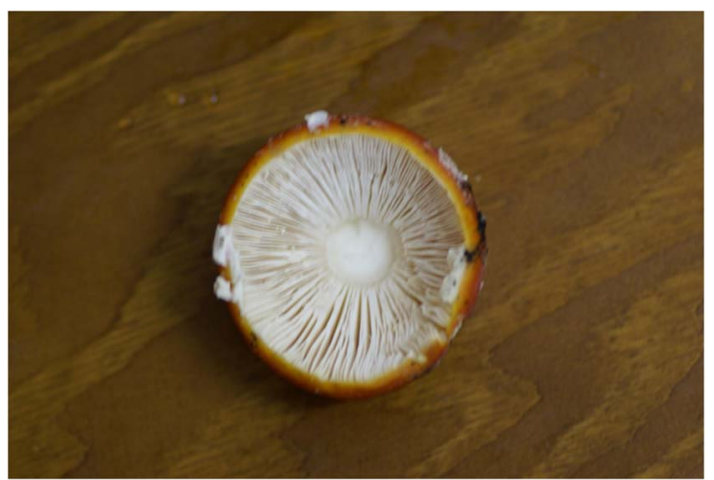

Figure 27. The gills of the mushroom can be seen as the spokes of a wheel

Both God Vishnu and his incarnation Krishna have a beautiful wheel as their most potent weapon to kill the "demons." The Buddha also had a "dharmachakra" (the wheel of law) that King Ashoka incorporated in his royal insignia, which has today become the national emblem of India. The wheel in this emblem (Figure 28) has found a place of honor in the middle of the Indian national flag.

Another form, a conch, can be seen as embedded within $A$. muscaria (Figure 29). To create the object in Figure 29, the unopened cap of $A$. muscaria was removed and the remains of the mushroom turned upside down. This bears a general resemblance to the fourth insignia of Vishnu, the conch,

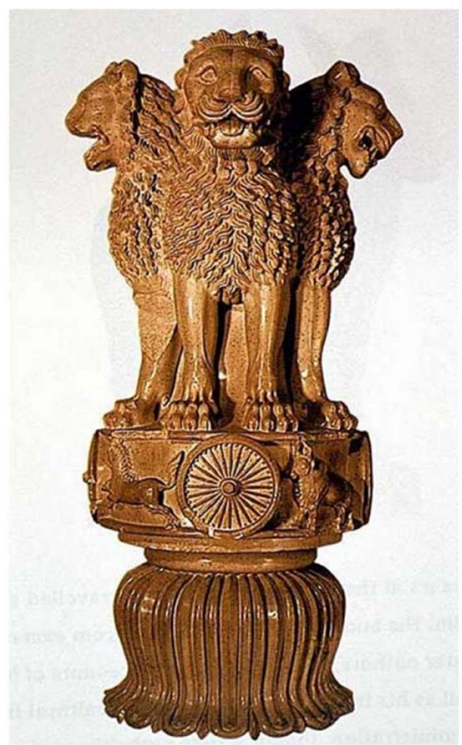

Figure 28. Buddhist King Ashoka's royal insignia accepted as the national emblem of India. Notice the wheel under the lions (source:

https://www.culturalindia.net/national-symbols/nationalemblem.html)

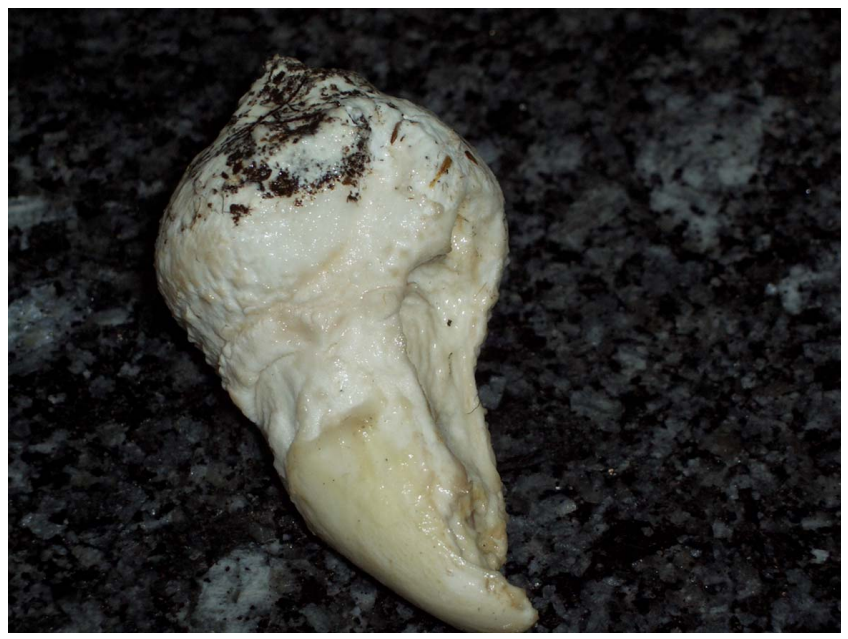

Figure 29. A "conch" created by removing the unopened cap of the mushroom and turning the mushroom upside down

which produces a reverberating sound that is supposed to scare away the "demons" and herald a "new era of righteousness." The "conch" is also associated with Krishna.

In Figure 30, we see the underside view of an A. muscaria that has been removed from the soil with dirt still adhering to the bulb. The upward protruding form has a penis-like shape, which looks like a "circumcised penis." This penis figure is one of the epithets of God Vishnu, expressed in the term "shipivishta," one meaning of which is "having no prepuce" (Monier-Williams, 1899, ID 216988).

With Figures 20-30, we have tried to show that the mushroom growth stages can encode insignia of Vishnu. The unopened cap with a longish stem can look like a lotus bud or a mace, the open cap looks like a beautiful wheel, and if the unopened cap is removed and the mushroom is turned upside down, it resembles a conch. We have also suggested 


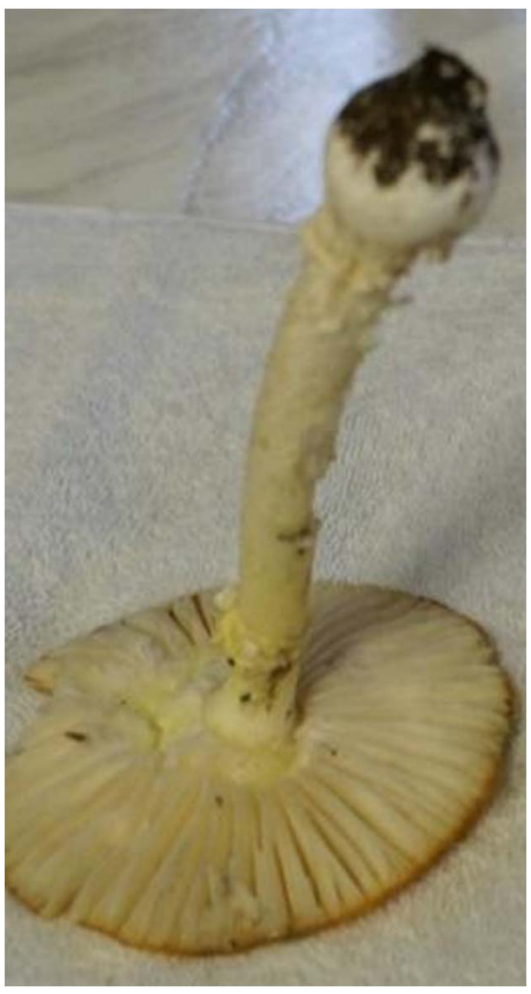

Figure 30. The stem and the bulb of the mushroom can look like a circumcised penis

that the mushroom cap could have become the iconic wheel of the Buddha, Vishnu, and Krishna, and the Buddha/Mahaveera's head with its typical jata-hairdress could be a representation of an entheogenic mushroom. Another icon of the mushroom, the "figure 8," will be elaborated later in the essay.

\section{FEATURES OF $P$. CUBENSIS}

The developmental stages of $P$. cubensis have substantially similar features to those of A. muscaria. Figures 31-34 (used with permission of John W. Allen) show the phases of the "figure 8," erupting heads, small barbells, and caps that parallel the forms of $A$. muscaria.

There is a close resemblance in the physical features of the two species; a notable exception is a ring (annulus) on the mid-stem and the lack of a bulb at the base for $P$. cubensis. There are other features that distinguish the species but they are not discernible on the pictures available of the Khajuraho sculptures. Figures 33 and 34 provide a clear depiction of the ring.

\section{Analyzing the mushrooms of Khajuraho}

In Table 1, we have presented the principal visual features of three entheogenic fungi known to Asia and India A. muscaria, P. cubensis, and Gymnopilus junoniu ("laughing gym;" see Guzmán, Allen, \& Gartz, 1998), as well as the observable features of several of the mushroom figures from the sanctuaries of Khajuraho. Given the limited depictions in the photos and the inability to clearly observe stem-gill

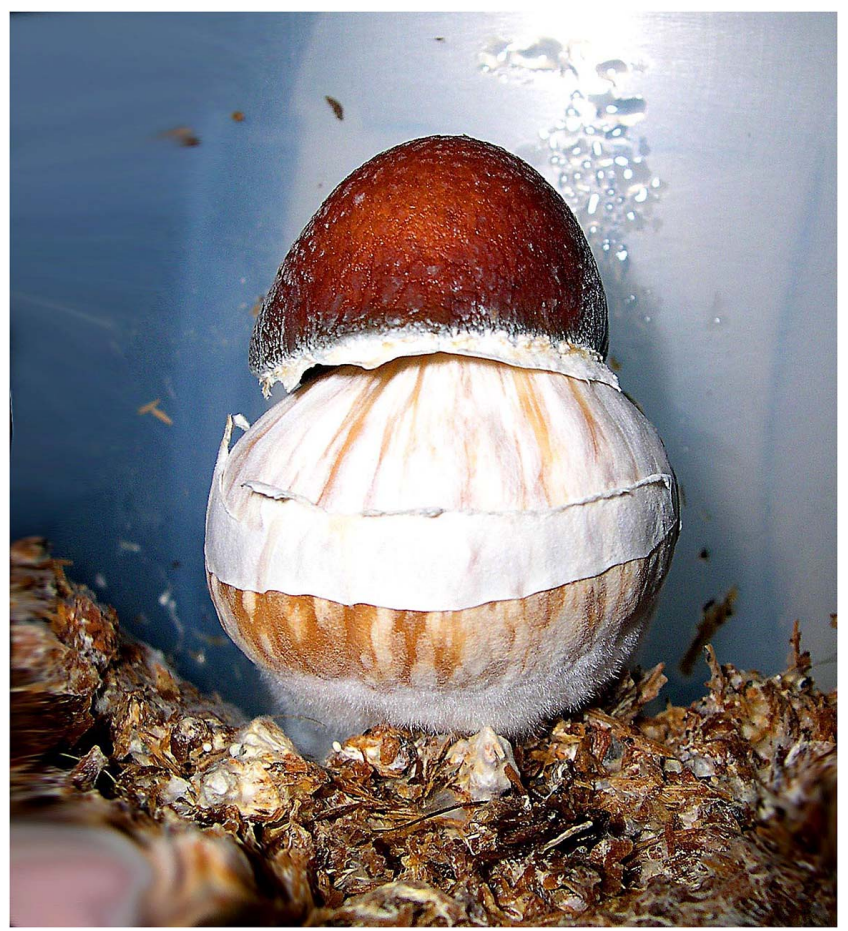

Figure 31. P. cubensis: "figure 8"-shaped "pot"

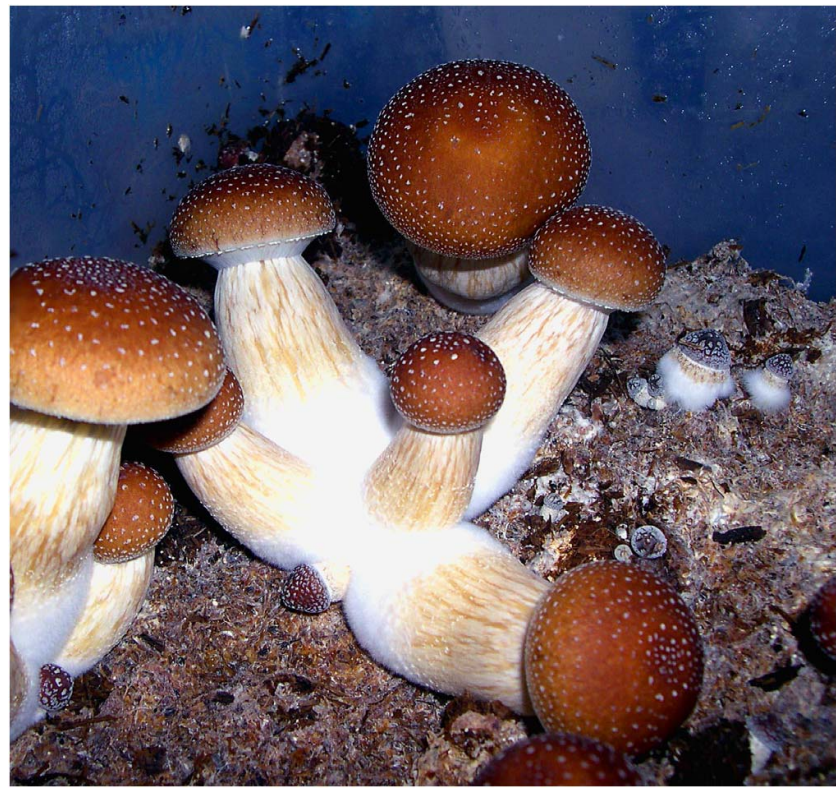

Figure 32. P. cubensis: a multiple-armed "deity" with "boomerangs" to kill "demons"

attachments and gill structure, the ability to identify which species these mushrooms represent is less than ideal. Nonetheless, using the criteria presented in Table 1, we can see that while one more closely resembles $A$. muscaria, the others manifest many of the characteristics more typical of P. cubensis.

The Vishwanath sanctum threshold mushroom has the obvious red color on the flat cap (but slightly hemispheric) and gills that appear free of stem, which are A. muscaria features. However, the wavy stipe, lack of an obvious volva, and the lack of an upper veil resemble $P$. cubensis, as does 


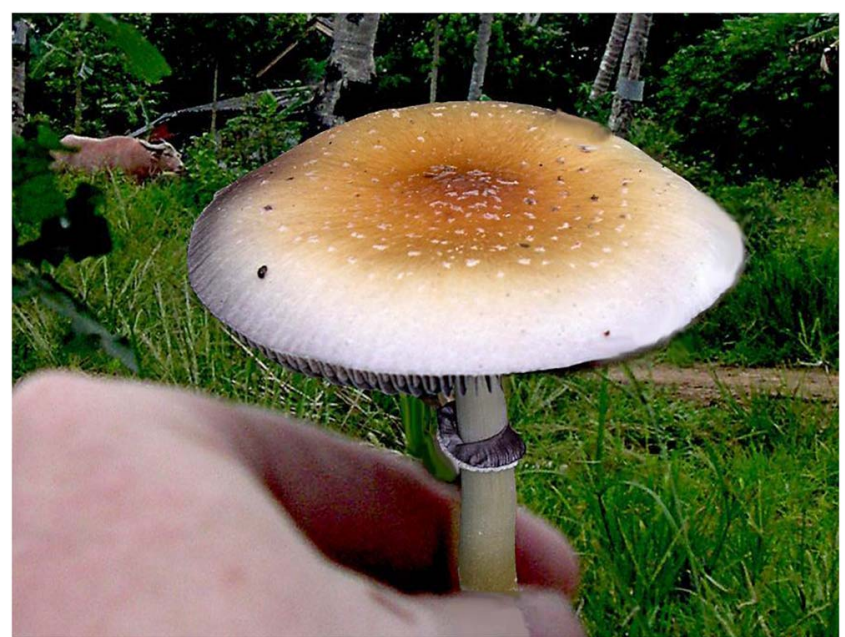

Figure 33. Ring on the stem of P. cubensis, Thailand

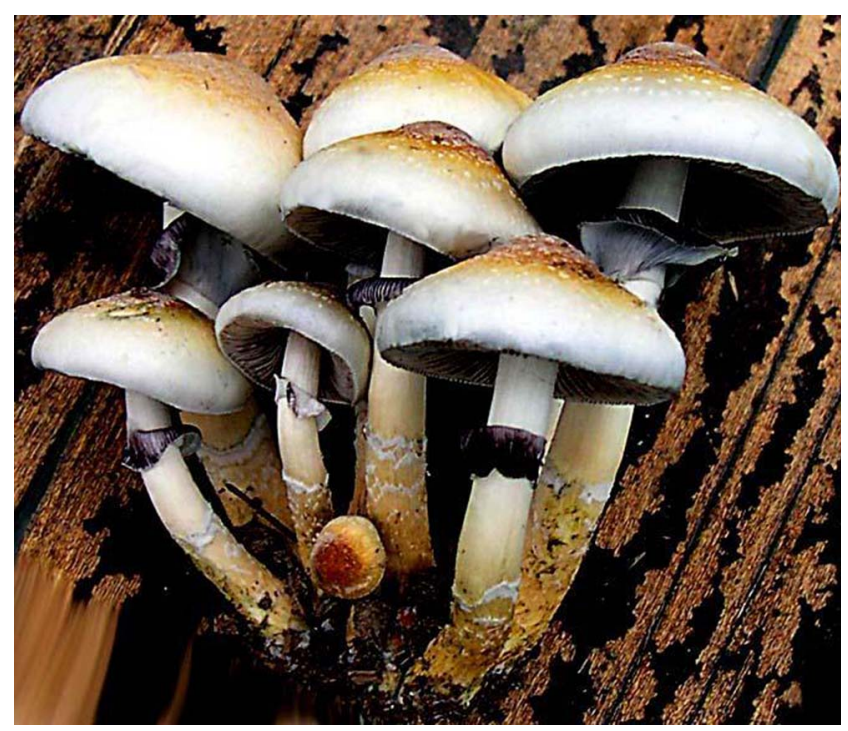

Figure 34. A cluster of $P$. cubensis with the rings on the stems

the stylized veil that may be present on mid-stipe, which thickens slightly toward base. There is no obvious volva characteristic of $A$. muscaria, but a stylized round base with ascending marks.

The Chitragupta sanctum mushroom presents a somewhat different profile in features more consistently associated with $P$. cubensis: a mostly yellow-brown cap with what appears to be adnexed gills and a wavy stipe thickening slightly toward the base and without an obvious volva. This mushroom lacks an upper veil, but with a possibly stylized veil at mid-stem.

The Jagdambi sanctum threshold mushroom presents another more similar to $P$. cubensis, with a yellow-brown cap that is broadly convex to flat and with gills appearing adnate. The stipe is also the characteristically slightly way, but the stipe is tan to slightly reddish, and with what appears to be a depiction of a universal veil attached to both cap and stem.

The mushroom at the Parshvanath sanctum threshold has a yellowish-brown cap with reddish specks and broadly convex to flat shape, consistent with $P$. cubensis, as is the possibly adnate gills. What is particularly compelling about the identity as $P$. cubensis is the two areas with blue spots on the center of the stem and above and below stylized annulus. These blue spots on the stem are indicative of the presence of psilocybin; nonetheless, the stylized red volva at base is not consistent with $P$. cubensis.

While we note that there are significant correspondences of the sanctum mushrooms with features of these species, but there is no unequivocal identification, in part given the similarities between $A$. muscaria and P. cubensis. But the real problem is that in some depictions there are contradictory indications.

For example, in the mushroom at the sanctum threshold (Figures 10 and 12), there is the distinctive red color and flat cap of $A$. muscaria, but instead of a straight stipe, upper veil, and bulb characteristics of $A$. muscaria, there is a wavy stipe, no upper veil and suggestion of a mid-stipe ring characteristic of $P$. cubensis. In the Jagdambi Temple mushroom (Figures 13 and 14), there is a yellow-red color, which could be any of the three mushroom candidates, a convex cap more typical of $P$. cubensis and $G$. junonius, and suggestions of veils at both the cap and mid-stipe of the mushroom. Why should the features of these possible candidates be mixed rather than a clear depiction of one of the candidate entheogenic species? Why do the sculptures of mushroom do not provide good clear unambiguous depictions of specific species of known entheogenic mushrooms, lacking accurate botanical depictions when it is obviously within the capabilities of the sculptors?

If the intention of the designers of the temple was to encode information yet leave it ambiguous to keep the uninitiated ignorant of the specific species, mixing up species characteristics would make sense. Secrecy would suggest tactics that suggest any number of entheogenic mushrooms but keeping distinguishing features vague or underrepresented. If it is the case that there were substitutes for an original soma, as has been argued by many researchers, it makes sense that the features of the various sources would be seen as interchangeable. The blending of the features would there be an encoding of their interchangeable nature.

Consequently, we propose that we should accept that these depictions are to encode entheogenic mushrooms in the temples rather than spiritually insignificant mushroom species. Everything about the location in a temple indicates that the interpretation should be entheogenic. The location of mushrooms in a sacred temple, and especially significant locations, such as the sancta thresholds, establishes that their purpose is to signify entheogenic experience. What could substantiate an alternative hypothesis that the mushrooms are presented in sacred temple reliefs as indications for culinary recipes or incidental and insignificant aspects of nature? Their very presence in a temple says that it is a sacred concern.

Combined with the dismemberment anomalies, these contradictions indicate that the Khajuraho Temple sculptures actually are designed to communicate a message different from that what they appear to be showing. The mushroom and dismembered sculptures are employing a symbolic language, called the "twilight language" or the "Sandhyaa Bhaashaa," an enigmatic language used to 
The "Kamasutra" temples and psychedelic spirituality

\begin{tabular}{|c|c|c|c|c|c|}
\hline 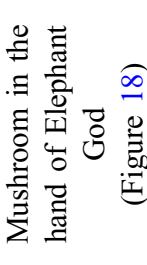 & 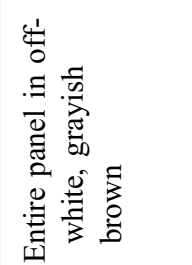 & 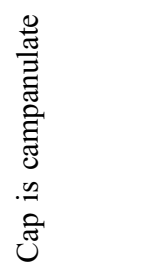 & 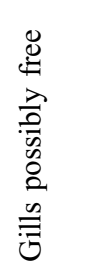 & 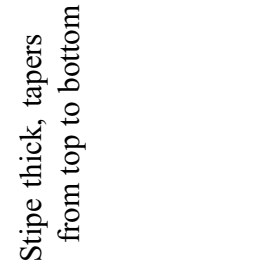 & 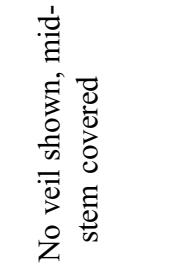 \\
\hline 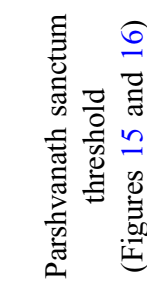 & 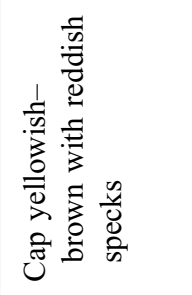 & 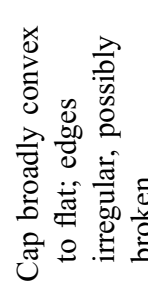 & 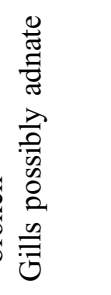 & 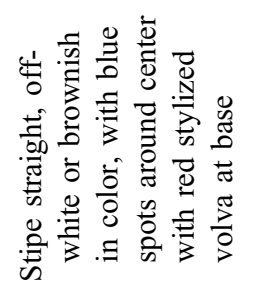 & 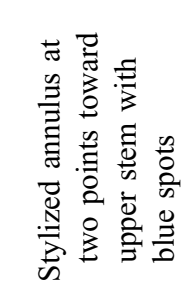 \\
\hline 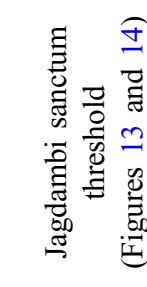 & 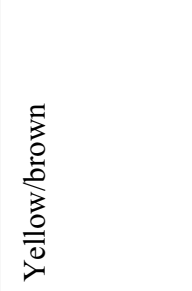 & 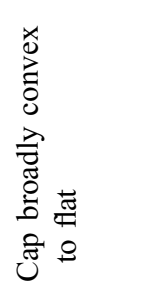 & 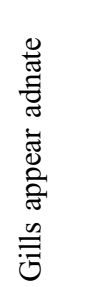 & 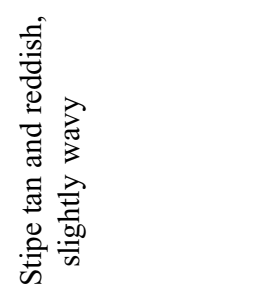 & 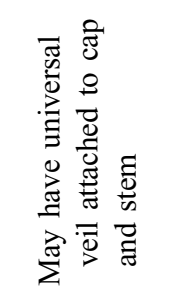 \\
\hline 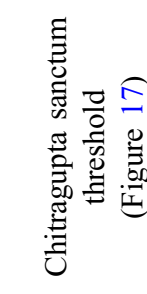 & 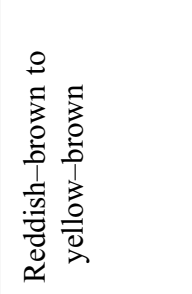 & 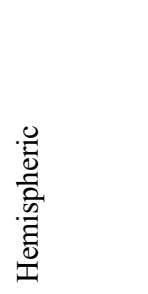 & 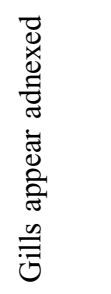 & 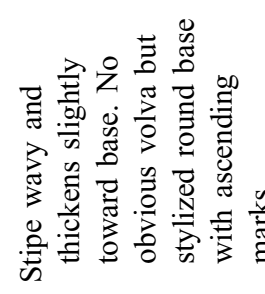 & 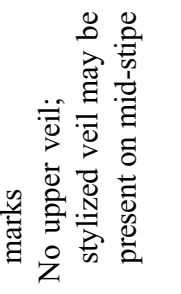 \\
\hline 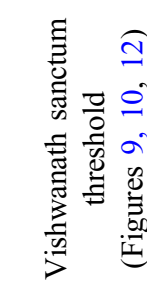 & $\begin{array}{l}\ddot{\Xi} \\
\simeq\end{array}$ & 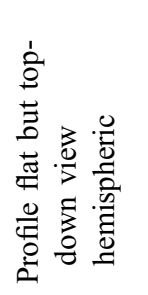 & 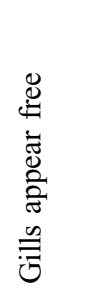 & 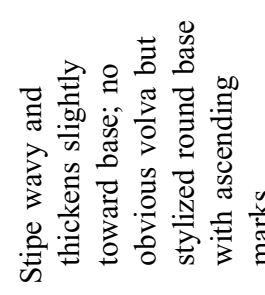 & 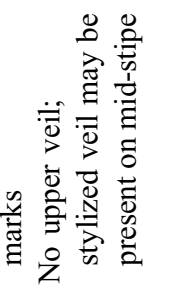 \\
\hline 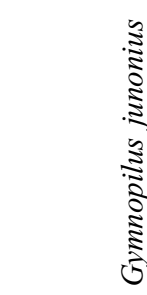 & 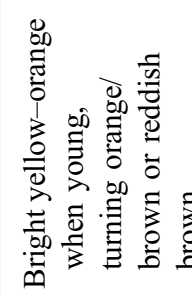 & 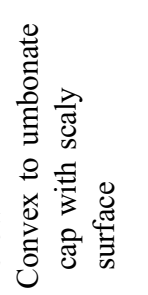 & 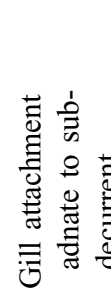 & 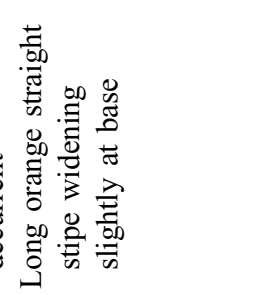 & 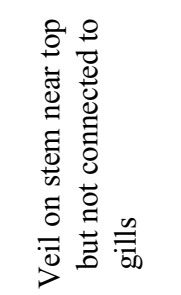 \\
\hline 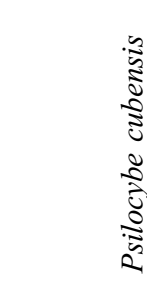 & 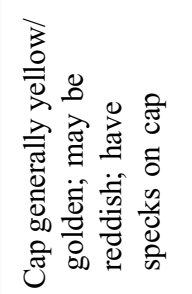 & 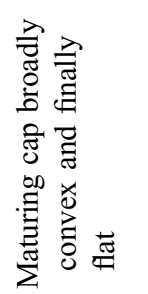 & 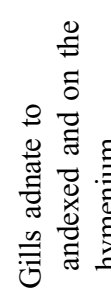 & 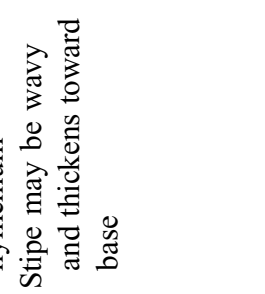 & 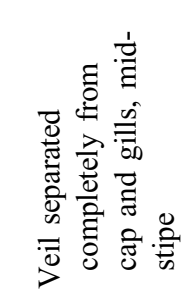 \\
\hline 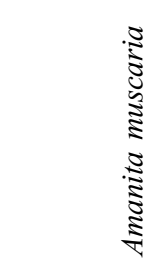 & 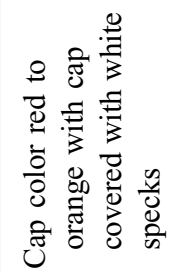 & 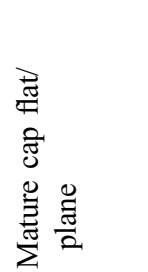 & 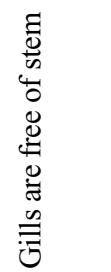 & 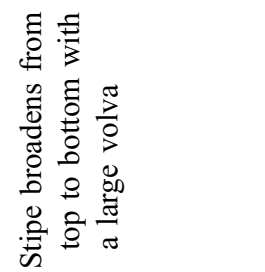 & 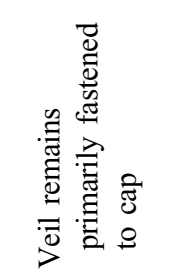 \\
\hline
\end{tabular}


obscure the meaning for the uninitiated while declaring its presence for the initiates (Hajicek-Dobberstein, 1993). It is worth noting that certain objects that are frequently depicted in Khajuraho have names with multiple meanings, one of which is "mushroom." For example, there are plenty of snakes/snake hoods depicted in the sculptures, and "ahi" means "snake" (21800), "chattra" means "umbrella" (75395) and "mushroom" (75389), so that "ahi-cchatraka" together - "snake umbrella" means "mushroom" (21824). To give two more examples, "karaka" means "water vessel" and "mushroom" (44234.7), "malli" means "flower" and "mallipatra" means "mushroom" (158869). Similarly, almost all Khajuraho statues are "girdled," and a Sanskrit equivalent of "girdle" is "kandali," which also means "deer," which is a gandharva (63285), a demigod, who is a guardian of soma (63278). It appears that mushrooms were depicted metaphorically in an iconic language. However, as it is stated earlier, there seems to be no Sanskrit word that explicitly means only "mushroom," as in English.

Is it a mere coincidence that Khajuraho sculptures abound in the depiction of flowers (as earrings), snakes, expanded snake hoods, water pots, and girdles, all of which are used to refer indirectly to "mushroom"? It is worth noting that two Sanskrit words connect "mushroom" with cow dung. "Shiliindhraka" means "mushroom, especially one growing out of cow dung" (217428). "Gomayachattraka" means "mushroom" (67373) but if we divide this word in two parts ["gomaya" means "defiled with cow dung" (67369) and one meaning of "chattraka" is "mushroom" (754339)], then we get the meaning "a mushroom defiled with cow dung." At present, why should these meanings exist in the dictionary unless $P$. cubensis was recognized as soma by the ancients?

\section{PARALLELS OF NAMES OF THE GOD VISHNU WITH CHARACTERISTICS OF ENTHEOGENIC MUSHROOMS}

An examination of the many names of God Vishnu reveals that some of them serve as an inventory of the identification marks of an entheogenic mushroom. Vishnu (202398) is a significant Hindu God. His incarnations include Raama [charming (177266), dark (177264), deer (177267)] and Krishna [dark/dark blue (55142) and antelope (55147)], the main characters of the two depicted in very important postVedic epics, the Ramayana and the Mahabharata. The literal meaning of the word "Vishnu" is "one who pervades (the universe, consciousness, etc.)." His legendary three steps cover the earth, the sky, and the mysterious world of God Yama, which we think is a reference to the effect of the entheogen God on the body, mind, and the spirit of man.

Vishnu's most important four insignia are: beautiful wheel, lotus, conch, and mace, which are the forms manifested in the different growth stages of an entheogenic mushroom as described above. He has one thousand names, which are regularly memorized and chanted by the devotees. The names of practically all other Gods of the Hindu pantheon, legendary characters, Jain prophets, and several synonyms of the Buddha are included in this list. A study of all his names and their thousands of synonyms is beyond the scope of this essay.
However, we have found a significant number of names that mean soma, or are related to soma, and several others, which seem to describe the characteristics of entheogens in general, and mushrooms in particular. All meanings are taken from Monier-Williams Sanskrit-English Dictionary (1899) and the ID numbers are given in brackets.

The 21 examples provided in Table 2 are names of Vishnu that either mean soma, or are directly related to it.

In addition to these words in Table 2, there are several names of Vishnu that have etymologically related words, which mean soma. For example, "chaturaha" means soma (71178) and "chaturaatmaa" is Vishnu; "chandra" is soma (71581) and "chandramshu" is Vishnu. "Aadityagraha" is a "ladle-full of soma in evening oblation" (23916) and "aaditya" is Vishnu, etc.

Some names of Vishnu indicate colors of the entheogenic mushrooms. For example, reddish brown/brown/deep brown colors of A. muscaria, P. cubensis, and G. jujonium are represented in the Vishnu names "Hari" (260897), "Kapila" (43542), and "Babhru" (142850). "Rohita" (180126) represents "red" or "reddish" that could be a pointer toward A. muscaria. "Hari" is a special name; it has meanings that include the principal colors of all three mushroom candidates we have mentioned. Hari also has many other meanings too, including practically all of the deities of the Vedas, Jainism, Buddhism, and Hinduism. "Yama," which has the meaning "dressed in blood-red garments" (170391), and "vaayu," meaning "with red and purple horses" (191228) are also Vishnu names, as well as meaning the colors of $A$. muscaria and $P$. cubensis, respectively.

Another point to note is that Vishnu's names correspond to the colors of certain specific mushrooms, not all mushrooms. For example, we could not find a name that means "gray" or "greenish-blue." Another interesting observation (mentioned earlier) is that Vishnu, Raam, Krishna, and Shiva (and others), which are the principal divine characters of the postVedic epics, are blue or blue-black, and all have "divine" birth, without human intervention. Isn't it possible that the post-Vedic epics have recast the story of the Rig Veda in new words with a new soma, referred to in their "blue" divine characters reflecting the unique colors of $P$. cubensis?

There are two names of Vishnu that have meanings that are shocking epithets for a God. The first is "shipivishta," which means "pervaded by rays," "leperous," "bald," and "having no prepuce" (216986). Usually only the first meaning is accepted as describing the God. However, if we keep an entheogenic mushroom in mind, then all four meanings make sense. Similarly, the name "udumbara" means "eunuch," "penis," and "a kind of leprosy" (30644). How can a God be described with such epithets? The name makes sense only if we think of it as describing one, or all the three mushrooms we have mentioned.

There are at least two names that seem to point toward the habitat of entheogenic mushrooms, such as like $A$. musaria and G. junonius. One is "shaambhava," which means Pinus deodara (215631), and the other is "shira," which means Betula bhojpatra (217096), two trees with which the mycorrhizal mushrooms live in symbiosis. Why should the names of a God include the names of these two trees?

Another name "gabahastinemi" is also very interesting. It means "the felly of whose wheel is sharp-edged" (63346). 
Table 2. Some names of Vishnu that are directly/indirectly related to soma

\begin{tabular}{ll}
\hline Name of Vishnu & \multicolumn{1}{c}{ Meaning } \\
\hline 1. Soma & Soma (252716) is Vishnu, Yama, Shiva, Kubera, one of the eight vasus and eight lokapalas \\
2. Somap & Drinking or entitled to drink soma juice (252839) \\
3. Sutpaa & Drinking the soma juice (245248) \\
4. Vasu & Soma (188707) \\
5. Madhu & Soma (155785) \\
6. Kavi & Soma (46515) \\
7. Daksha & Strengthening intellectual faculties: soma (89318) \\
8. Prajaapati & Soma (130885) \\
9. Aadideva & Sun (23837), which means "anshumat," which in turn means "rich in soma plants or soma juice (66)" \\
10. Yama & Dharma, which means "soma drinker" (99920) \\
11. Brahman & Soma vessel of Brahman priest (147327) \\
12. Rudra & Kavi (178525), which means soma (46515) \\
13. Raam & Deer (177267). Deer is a gandharva (63285), a demigod who is a guardian of soma (63278) \\
14. Pavitra & A particular soma sacrifice (120447) \\
15. Savitra & Sun (23837), which means "anshumat," which means "rich in soma plants or soma juice (66)" \\
16. Yaj & To worship, adore, and honor (especially with sacrifice or oblations) (169114) \\
17. Vanaspati & Lord of plants: the soma plant (185990.10) \\
18. Dharma & A soma drinker (99920) \\
19. Vaachaspati & "Lord of voice or speech," applied to soma (190184) \\
20. Suruchi & Name of a gandharva king (248723). Gandharva is the guardian of soma (63278) \\
21. Avyaya & Made of sheepskin (as the woollen soma strainer) (19307) \\
\hline
\end{tabular}

This could refer to identifying marks of $A$. muscaria, which has a typical "grooved" edge that distinguishes it from similar-looking, but deadly poisonous Amanita phalloides (Flück, 2009, pp. 230-232). Grooved edge of the cap also distinguishes A. muscaria from P. cubensis and G. jujonium. "Gabhastinemi" should be compared with "arishtanemi," which means "the felly of whose wheel is unhurt" (15374), and which is the name of Vishnu and the 22nd Jain prophet. There is another name "taarakshya" connected to "arishtanemi," which is associated with "garuda," the falcon vehicle of Vishnu, and several demigods: gandharvas, yakshas, and charanas (8445), which could be the spiritual beings traditionally believed to inhabit the entheogenic mushrooms.

Another interesting name of Vishnu is "kshar," which means "to urine" (59141). Why should a God have such a name? Couldn't this name be a pointer to the tradition of drinking the urine of the mushroom partaker to get the benefits of the entheogen? In this case, the name could be a direct pointer to A. muscaria. "Kshar" also means perishable. How can a God be perishable, unless he is also seen as a fragile mushroom?

There are other names of Vishnu that describe seasonality, appearance, texture, and the physiological/psychological effects of the entheogenic mushrooms. Table 3 displays these names.

A reddish brown and bald God, who hops around on one leg, who is a leprous eunuch with a circumcised penis, connected to pine and birch trees, and who is difficult to find exemplifies features of $A$. muscaria. The God, which is a sleep-inducing medicine, and who has a sharp-edged wheel, seems to be a strong candidate for being $A$. muscaria and the God, which can have blue and purple colors, is a pointer toward $P$. cubensis, which typically turns bluish when bruised. The post-Vedic dates of the blue Gods are an indirect form of evidence for the transitions from use of A. muscaria to P. cubensis.

\section{ENCODING THE “FIGURE 8" SYMBOL}

The "figure 8" symbol produced in the early growth stage of A. muscaria is found in a variety of aspects of Khajuraho sculptures. "Figure 8 " is not only the shape of young A. muscaria, but also the shape of the universal mathematical symbol representing infinity or eternity, which is a name of Vishnu. A word "vasu," some synonyms of which are names of Vishnu, means "the number eight" (188710). Interestingly, "vasu" has other synonyms that in turn are synonyms of almost all Gods, immortal beings, several plants, and also of the word "immortality." "Vasu" also means "a particular drug" (188728). All these meanings and names of deities get connected to "figure 8" of the mushroom through the word "vasu."

The significance of the resemblance between the "figure 8" and the young stage of the sacred mushroom seem to be that the eternal and the infinite element of the Sanatan Dharma (the eternal religion), a most important epithet of all-inclusive Hinduism, which could be symbolized by the entheogen A. muscaria. The word "Hindu" comes from Persian (262938), which must have had its origin in the word "indus," the "country" around which was also called "sindhu" (244818), which is also a name of Vishnu (244820). Therefore, "Hinduism" can be seen as a cover term for all ideologies, religions, cults, faiths, and sects that are a part of the Indus Valley Civilization. In its macroscopic form, Hinduism is not a "religion": it is the "way of life" of the peoples of the Indus Valley Civilizations. "Figure 8," which we have proposed to be an important icon of the mushroom, can be an underlying golden thread of connection, which can collate many disjointed sculptures of seemingly different religions, and reveal that they actually belong to one fundamental, eternal religion of entheogenic spirituality. 
Table 3. Names of Vishnu referring to mushroom characteristics

\begin{tabular}{|c|c|c|}
\hline Name of Vishnu & Meaning & Comment \\
\hline \multicolumn{3}{|l|}{ Seasonality } \\
\hline Saanvatsara & Annual (240881) & Most mushrooms appear only once a year \\
\hline \multicolumn{3}{|l|}{ Appearance } \\
\hline Padmanaabha & Lotus-naveled (115604) & The inverted cap of the mushroom can look like a lotus with a navel \\
\hline \multirow[t]{4}{*}{ Pundareeka } & 1. White umbrella (125261) & P. cubensis can look like a white umbrella when it is young. "Lotus" is one \\
\hline & 2. A sacrifice $(125265)$ & of the four insignia of Vishnu. Leprosy spots are symbolic of the \\
\hline & 3. A leprosy (125273) & universal veil remains on the cap of mushrooms. The entheogens are \\
\hline & 4. A drug (125262) & considered to be medicines \\
\hline Ekapaada & $\begin{array}{l}\text { Having or using only one foot } \\
\text { (39433) }\end{array}$ & This name could be a reference to a mushroom with a stipe \\
\hline Shataavrata & $\begin{array}{l}\text { Having a hundred tufts or curls on the } \\
\text { head }(212325)\end{array}$ & $\begin{array}{l}\text { This name could refer to the remains of universal veil on the cap. It could } \\
\text { also refer to the Buddha or the Mahaveera head always depicted with curls }\end{array}$ \\
\hline Kanakaangada & Golden bracelet (42922) & $\begin{array}{l}\text { If we see the stipe of the mushroom as an "arm", the ring or the annulus on } \\
\text { it can be metaphorically seen as a "golden bracelet" }\end{array}$ \\
\hline \multirow[t]{2}{*}{ Sushena } & $\begin{array}{l}\text { 1. Having beautiful clusters } \\
(2502557)\end{array}$ & $\begin{array}{l}\text { A. muscaria often is solitary, but a whole family of } A \text {. muscaria (and } P \text {. } \\
\text { cubensis) can be found together, looking like a bright cluster }\end{array}$ \\
\hline & 2. Having a good missile (2502556) & \\
\hline Ghritshree & $\begin{array}{l}\text { Brilliant with ghee (purified butter) } \\
\text { (70017) }\end{array}$ & $\begin{array}{l}\text { The cap of } A \text {. muscaria is brilliant and the slimy spore secretion on it can } \\
\text { look like ghee, which makes it look more shiny }\end{array}$ \\
\hline \multicolumn{3}{|l|}{ Texture } \\
\hline Peshala & $\begin{array}{l}\text { Soft, delicate, tender (128999) } \\
\text { Clever (129000) }\end{array}$ & $\begin{array}{l}\text { Entheogenic mushrooms are easily breakable, soft, and their effect can } \\
\text { cleverly alter the mind of the partaker }\end{array}$ \\
\hline & Fraudulent (129001) & \\
\hline Drida & Fixed, firm, solid (95074) & $\begin{array}{l}\text { Reference to the texture, the firmness, and the non-flexibility/non- } \\
\text { elasticity of the mushroom tissue }\end{array}$ \\
\hline Gabheera & Dense, impervious (63363) & $\begin{array}{l}\text { Reference to the texture. Fresh, edible mushroom is not porous or "leaky." } \\
\text { Dried mushroom can absorb water but it still does not become porous }\end{array}$ \\
\hline \multicolumn{3}{|l|}{ Effects } \\
\hline Vishodhana & Cleansing, Purging (200776) & Reference to the physiological effect \\
\hline Swaapana & $\begin{array}{l}\text { Causing to sleep (said of a mystic } \\
\text { weapon) (259041) }\end{array}$ & $\begin{array}{l}\text { A. muscaria is known to initially induce a period of sleep before more powerful } \\
\text { effects occur. The "mystic weapon" could be the sacred mushroom }\end{array}$ \\
\hline \multirow[t]{3}{*}{ Uttara } & 1. Vomiting (31439.4) & Reference to the physiological and psychological effects of the mushroom. \\
\hline & 2. Rescuing (31439.2) & The nausea could be a pointer toward $A$. muscaria \\
\hline & 3. Transporting over (31439) & \\
\hline \multicolumn{3}{|l|}{ Miscellaneous } \\
\hline Ratna-naabhaa & One whose navel is a jewel (174316) & $\begin{array}{l}\text { Navel is an important symbol. The mushroom has a navel and its effect } \\
\text { starts from the human "navel" after ingestion }\end{array}$ \\
\hline Amaanin & Not proud (14057) & $\begin{array}{l}\text { Amaanin means "not proud"/"modest" (14057). Amanita (f.) is a Sanskrit } \\
\text { word which also means modesty or humility (14058) }\end{array}$ \\
\hline \multirow[t]{3}{*}{ Dvija } & 1. Twice-born (98441) & It is interesting that the epithet "dvij" which means "twice-born" is \\
\hline & $\begin{array}{l}\text { 2. A bird or an oviparous animal } \\
\text { appearing first as an egg ( } 98801)\end{array}$ & $\begin{array}{l}\text { applicable to the mushroom because it is first born as an "egg" before it } \\
\text { takes the form of a mushroom }\end{array}$ \\
\hline & $\begin{array}{l}\text { 3. A tooth because it grows twice } \\
\text { ( } 98802)\end{array}$ & \\
\hline
\end{tabular}

We start the study of "figure 8" with Figure 35 of God Agni, taken from the Internet.

In Figure 35, we see a figure with the "broken" right hand and knee, sitting on a cow-like animal in this picture. This figure in the Museum Guimet, Paris, is identified as the God Agni. Even if we accept that a vandal cut off the forearm and the knee, how could he have joined the right foot to the right upper thigh? Where in that case did the right lower leg/ankle of the statue disappear to? A careful examination of this sculpture would suggest that it is not damaged. This broken shape has been painstakingly sculpted by the artist to encode the "figure 8 " shape of A. muscaria; also see
Figures 36 and 37 to understand what one half of the vertical section of the "figure 8" stage of A. muscaria looks like and how it could have been encoded in Figure 35.

Figure 37 gives another view of the mushroom shown in Figure 36 to make it clear how it can look like "figure 8." Isn't one of these pieces encoded in Figure 35?

Coming back to Figure 35, there are several important points to be noted with regard to this picture of Agni, the God of fire:

1. "Figure 8," or the symbol of infinity, is created through a deliberate severing of the right hand and the right-folded leg of Agni. If the anatomy were 


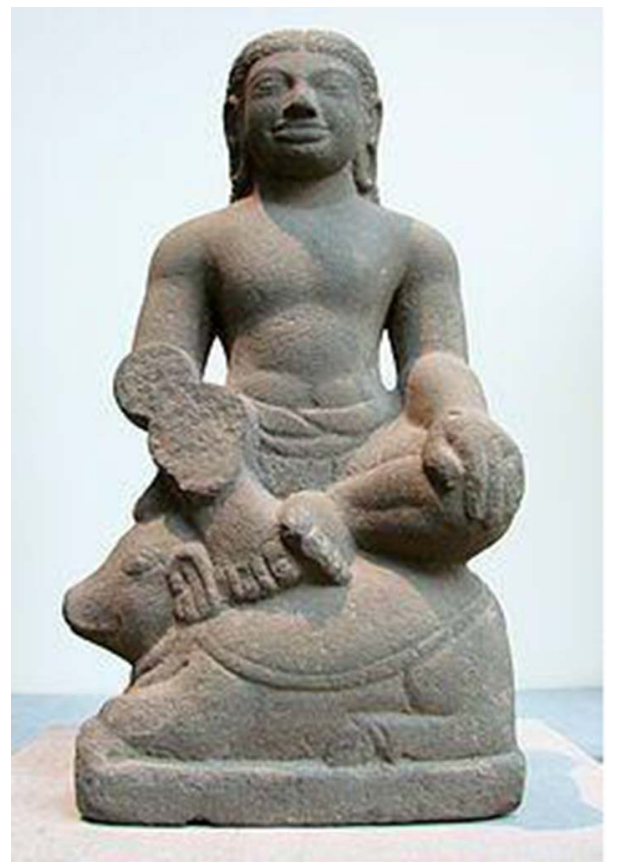

Figure 35. The association of Agni, the God of fire, with a "figure 8 " in a broken appearance of a statue in Guimet Museum, Paris (source: 7th century sandstone sculpture of "Agni" in Museum Guimet, Paris; https://commons.wikimedia.org/wiki/File:Mus\% C3\%A9e_Guimet_897_05.jpg</comment)

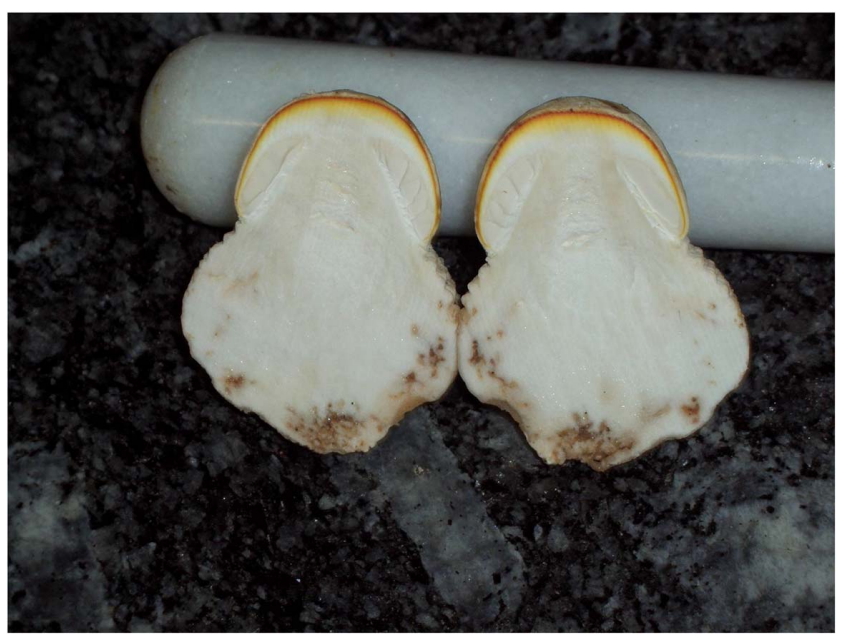

Figure 36. Inner side of the figure 8 stage of $A$. muscaria, vertically sliced in two parts

depicted correctly, there should have been round round stumps: one of the wrist, second of the thigh, and third of the lower leg. But we see only two stumps. Therefore, the "mutilated" area cannot be taken as an act of vandalism. The artist has deliberately created an anatomical anomaly.

2. The above statue does not depict Agni as a human or a God holding the mushroom in his hand. Instead, the hand has been severed to carve the "figure 8" shape. The implication of this deliberate act is that Agni and the mushroom are not two separate entities but that Agni is the personification of the mushroom.

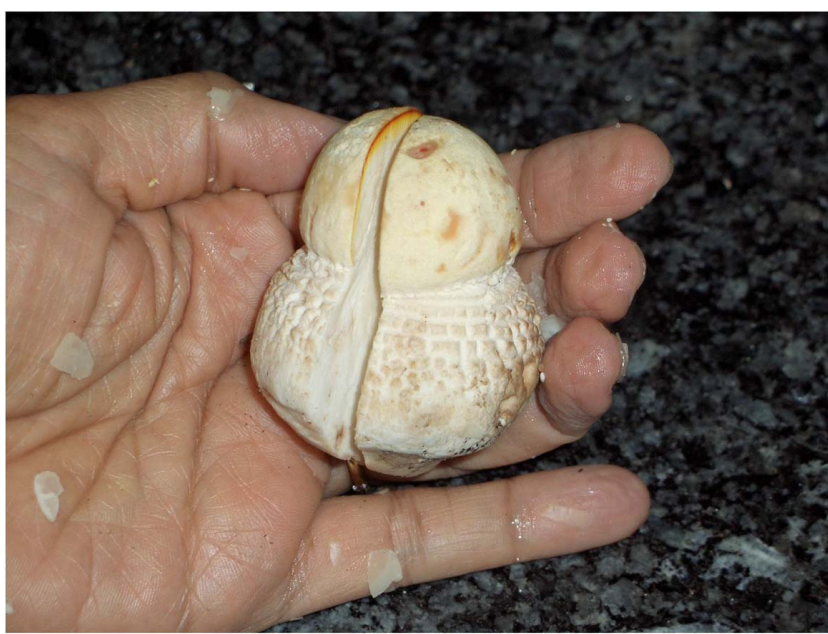

Figure 37. Side view of the figure 8 stage of $A$. muscaria vertically sliced in two parts

3. The sculpture is a monolith. Therefore, the "cow-like" animal and the "God" sitting on it are not two separate beings. They are both functioning together as an iconic representation of the mushroom. Incidentally, Vishnu's name "Kapila" (43522), which we have given above in connection with the reddish-brown color of the entheogenic mushrooms, also means "cow" (43540) and "a kind of fire" (43535). Similarly, "karveera" is a "species of soma" (44167) and "karveeree" is a "good cow" (44179). Therefore, it seems that "cow" is an important icon associated with soma and Agni, and may implicate the additional entheogenic identity of soma in the Psilocybe species that grow in cow dung.

Figure 35, which is not from Khajuraho complex, establishes a precedent for a deliberate depiction of a "figure 8 " in Agni within the context of what appears damaged, but which is an impossible distortion of human anatomy. This suggests that we examine similar "disfigured" or "vandalized" sculptures of Khajuraho in a similar light.

It is highly interesting that almost a similar "figure 8," which we have seen in Figure 35 on Agni sculpture, is encoded in the "damaged" knee and thigh of Jain prophet, Mahaveera in the Archaeological Museum, Khajuraho, shown in Figure 38. The clear cut of the "shape" reveals that this is not vandalism, but rather a deliberate act of the sculptor.

Figure 39 shows the statue in Figure 38 from the front view. Note that the front of the statue is intact. Why would a vandal break the knee and thigh so neatly and stylistically, and leave the rest of the statue intact? This "figure 8" shown in Figure 38 is a pointer that the sculpture of Mahaveera, a contemporary of the Buddha, was meant to encode entheogenic mushrooms.

Figure 40 shows how "figure 8 " is encoded in the "damaged" breasts of a beautiful apsara (celestial damsel). The clean cut again suggests deliberate modification rather than vandalism.

Figure 41 shows a "headless" statue encoding a "figure 8" in place of the head. The right breast also encodes "figure 8." This sculpture is a good example that headlessness of the statues was symbolic of an egoless state of mind, and it served 


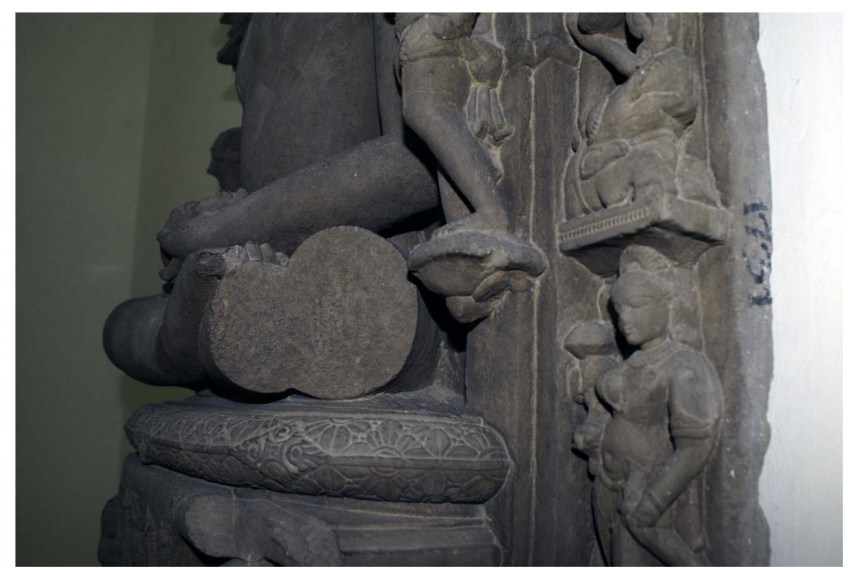

Figure 38. "Figure 8" created in the "damage" on the left knee and thigh of Jain Mahaveera. Archaeological Museum, Khajuraho

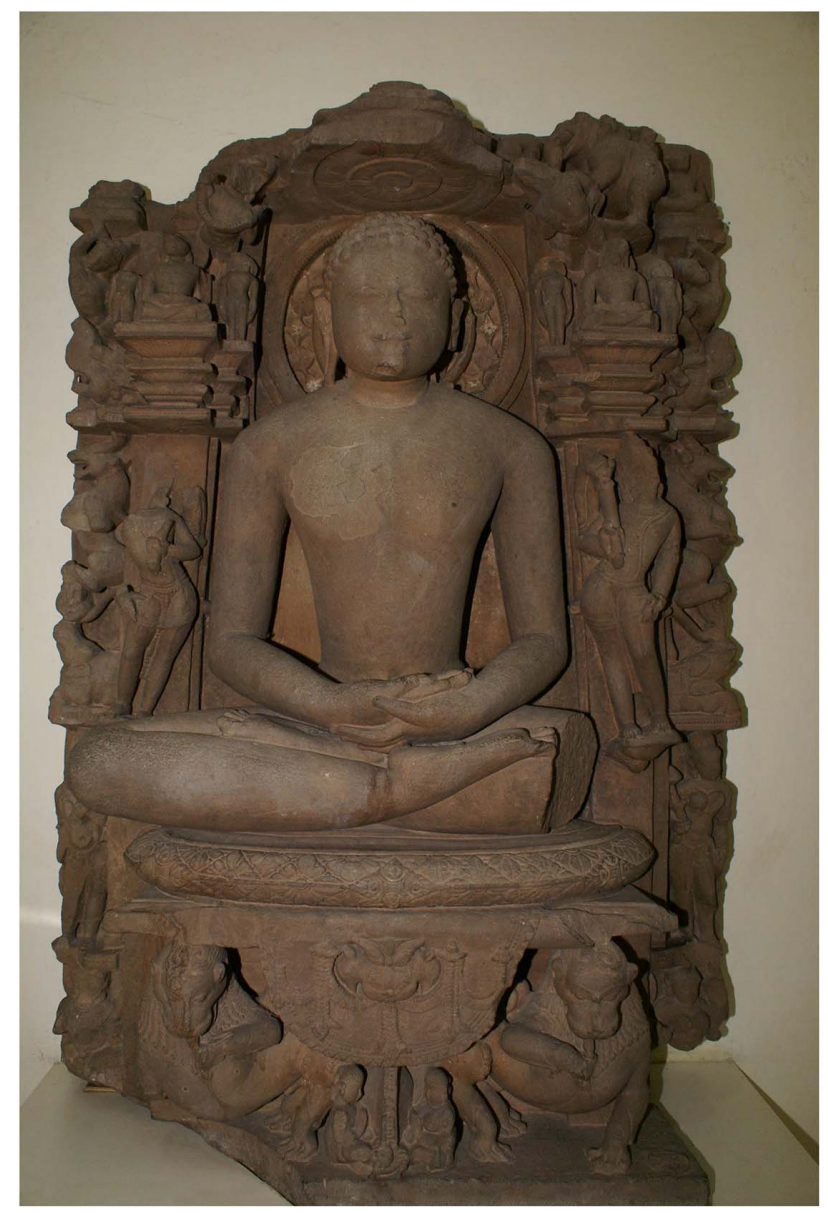

Figure 39. Front view of Jain Mahaveera in Figure 38 with figure 8 encoded in left knee and thigh, Archaeological Museum, Khajuraho

as an artistic device to encode entheogens, the tools to reach that egoless state.

Is it possible that all the sculptures that encode the "figure 8" are references to "forms" of the God Agni? Agni is the first and foremost God invoked in the Rig Veda, in the very first hymn, to bring the other Gods to the soma ceremony. Furthermore, most of the Vishnu names in Table 2 meaning soma also mean Agni. This implies that Agni, Soma, and $A$.

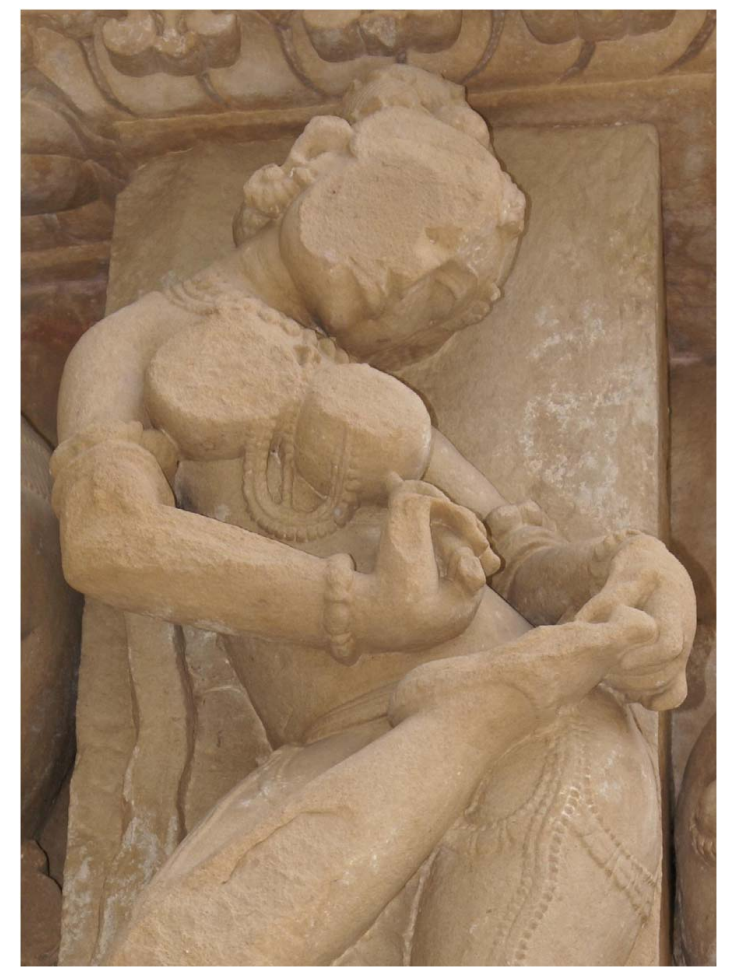

Figure 40. Figure 8 in the "damaged" breasts, Parshvanath Temple, Khajuraho

muscaria are synonyms of one another. It is indeed intriguing that a serpentine "figure 8 " is encoded on both sides of the stem of the mushroom sculpture at the sancta thresholds in Figures 10, 13, and 17. This serpentine "figure 8" gets repeated very often in Khajuraho Temples.

In wrapping up this essay, we further examine this feature of "headlessness" to show how this feature depicted in the Khajuraho Temples picturesquely depicts central concepts of spiritual development.

The concept of "no head" or "headlessness" as a developmental phase for entering into enhanced spiritual awareness has a history across religious traditions, paralleling the better known emphasis "no self" or "selflessness" (Harding, 2002). Harding characterizes this condition of an awareness of one's own "headlessness" as a reflection of one's ability to see into one's own true nature. This realization is often embedded in aphorisms about being beheaded or losing one's head, concepts expressed across many traditions that attest to a vision of the potentials of human consciousness that transcend the specifics of local cultures and traditions. This is a reflection of a phenomenological reality of one's "facelessness," a part of the nature of one's being that is generally inaccessible to one's awareness.

Harding explains the emphasis on the disappearance of the head, especially the face, as something that is always absent in our experience, but not in awareness.

This experience of headlessness is a reflection of the primitive awareness of a baby in its experience of the world, where awareness of one's own body is limited, and experience of one's own extended body in space emerges slowly. The consciousness of an infant is not separated from the world in an absence of awareness of one's own nature and condition, an un-self-consciousness that is focused outward 


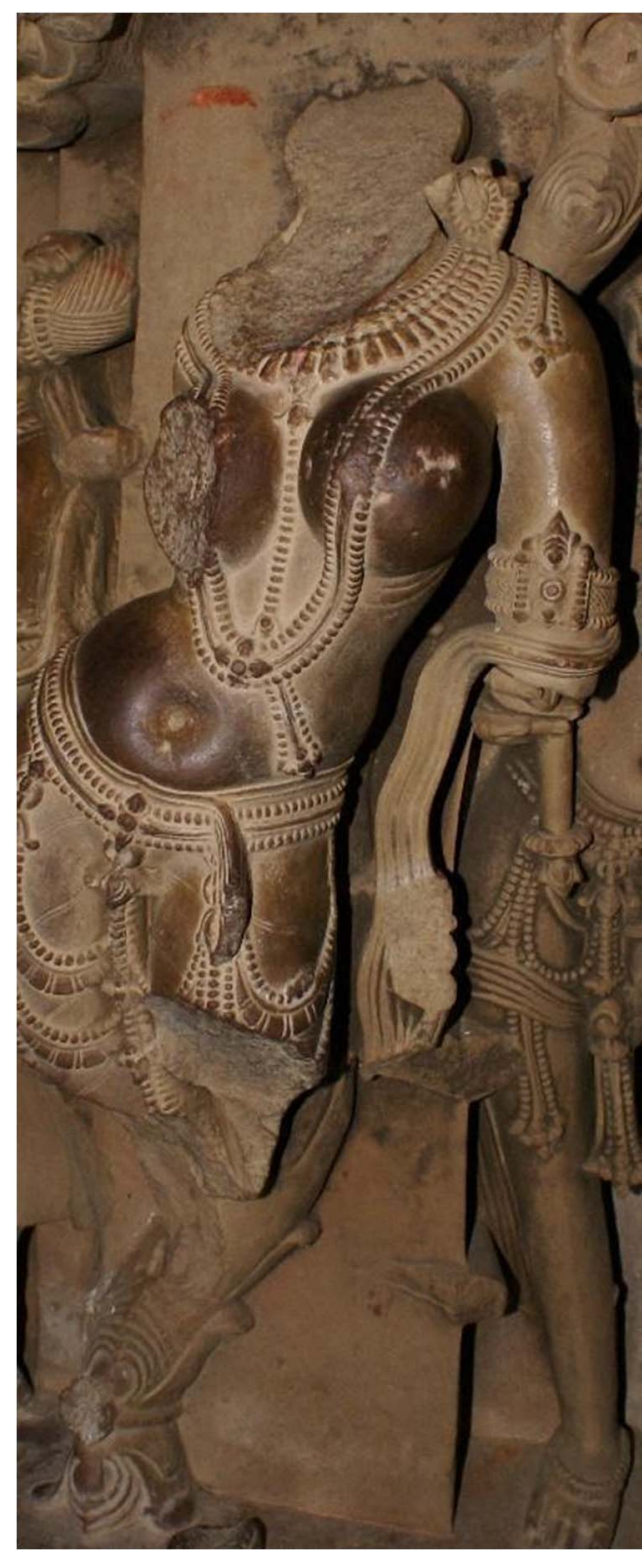

Figure 41. "Figure 8" in place of the head, Jagdambi Temple, Khajuraho

and unaware of one's own presence (p. 86). "Here is manifested the unsophisticated self which is the Original Face of your being" (Harding, 2002, p. 58).

Echoing the words of Harding, Khajuraho Temples depict the icon of a headless baby in the arms of beautiful apsaras (celestial damsels) frequently found in the sculptures (Figure 42).

Consequently, the adult losing of one's head is different from the baby's condition in that the adult has an awareness of head and body that is subsequently lost. This headless state is the beginning of spiritual life, a form of true seeing, a "seeing into No-thingness [that] is consciously connecting up with the source of all thingness" (Harding, 2002, p. 100). This headlessness is a manifestation of the void, an experience of a "hole where a head should have been" (Harding, 2002, p. 45) and a body filled with emptiness. This seeing of one's true face and void nature is the realization of satori, seeing into the

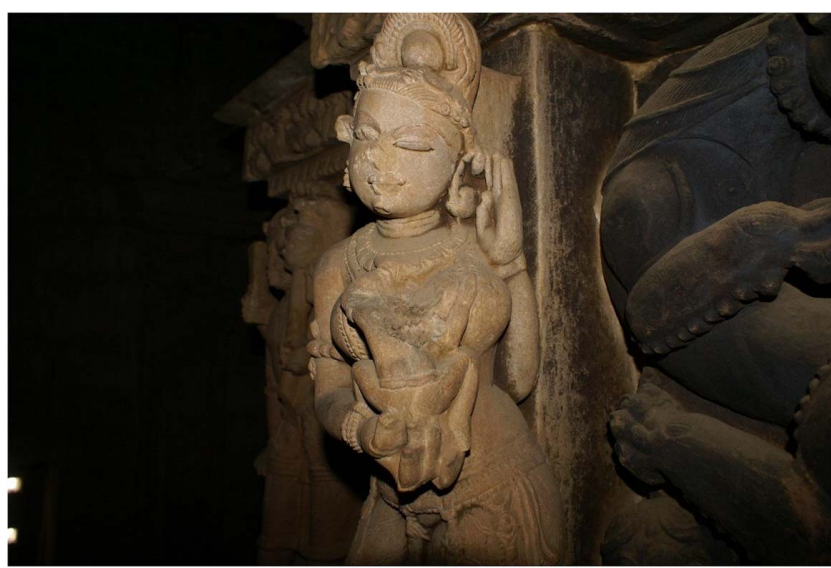

Figure 42. Headless baby in the arms of an apsara. Vaman Dev Temple, Khajuraho

timeless nature of our being (Harding, 2002, p. 81). "Present experience, whatever sense is employed, occurs only in an empty and absent head" (Harding, 2002, p. 33).

The experience of "a hole where a head should have been" is enshrined in Javari Temple, Khajuraho, by installing a 9-ft-tall headless Deity in the temple sanctum as shown in Figure 43.

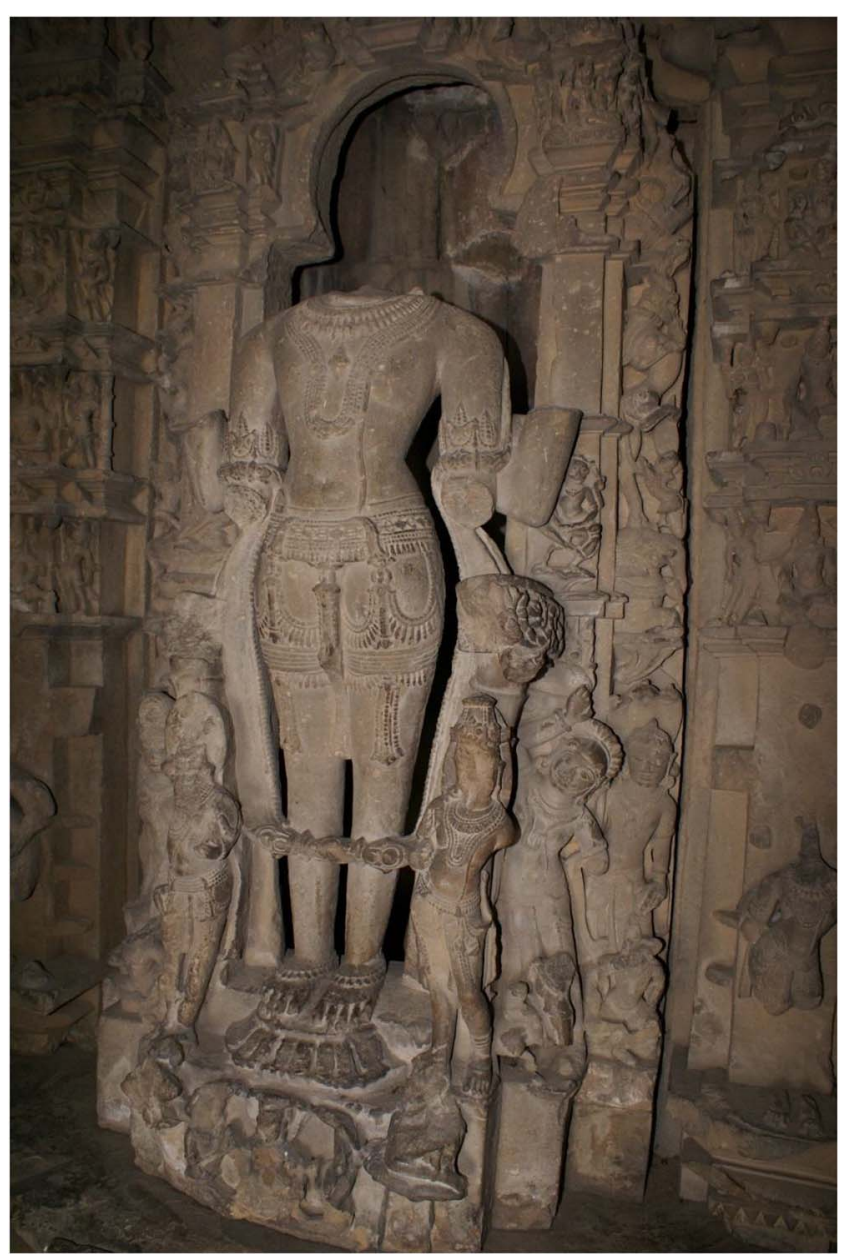

Figure 43. The headless main Deity in the sanctum of Javari Temple, Khajuraho 


\section{CONCLUSIONS}

The essay has presented evidence that $A$. muscaria icons are encoded on Vishnu, Agni, the Buddha, and the Mahaveera sculptures and therefore they are all $A$. muscaria deities. This also means that the Buddhist Wheel of Dharma, which King Ashoka took as a part of his royal insignia, may also represent $A$. muscaria. If more than a billion people of India would really understand the significance of the icon in their national flag, the "Wheel of Law" of the Buddha could be set in motion, which means profound personal, cultural, and global changes could start taking place in the world. If it is true that the deities of all-inclusive Hinduism are the A. muscaria deities, it will have far-reaching consequences for an interpretation of the Hindu, Jain, and Buddhist religious texts. The entire socioreligious and political history of India may need to be reviewed afresh in the light of this observation.

Khajuraho was culturally highly developed as reflected in the exquisite workmanship of its temples. Built between AD 900 and 1130 (Mitra, 2002), the temples are about a thousand years old. This means that there is at least 10,000 years of history of using $A$. muscaria as a sacrament, starting from the Siberian use and continuing through the Aryan invasions, the writing of the Rig Veda thousands of years ago, and the construction of temples during Buddhist and Jain times at least as late as 1130 AD. In other words, the worship of entheogens was an essential part of the cultural and religious fabric of ancient India for most of its existence. This tradition of entheogen use spanning thousands of years, which the modern rational mind may reject outright, creatively anchored the intellectual and spiritual growth in that civilization.

It is clear that entheogenic mushrooms are encoded in the beautiful temples of Khajuraho. The mushroom sculptures present at the sancta thresholds of the temples, whether A. muscaria or other entheogenic mushrooms, show that these natural substances, embodied as a stepping stone to the sanctum, are indispensable tools to open the "brain" of the temple body, the "home" of the divinity. This key mushroom placement visually and physically demonstrates that the doorway to the transcendental spiritual world goes through effects of entheogenic mushrooms on the human brain.

The Khajuraho sculptures make a spiritual statement in stone that most of the time we "see" what our conditioned mind shows us and miss the underlying reality. The pictures of the erotic sculptures appear to exhibit humans involved in group sex; so overwhelming are the visuals that they hardly let us think of any other possibility. Yet the careful study of the details of the sculptures suggests that the reality can be very different from what it appears to be in a particular context. Our failure to see the anatomical distortions in the sculptures leads us to the realization that our mind plays games with us. As the mist hides a mirror, or the smoke hides a fire, the mind fluctuations or the vrittis [Five Vrittis are five modes of consciousness: explicit knowledge (which can be correct and incorrect), imagination, deep sleep, dreams, and memory. These five "modes of being" (of our mind) generate thoughts, create our "reality," and keep us busy by constantly restructuring this reality, which actually is "fiction" because it is only a creation of our mind. This is "avidya" (illusion), the root cause of all other human problems] clouds the truth of our divine form from us. The conditioning of our brain, resulting from the vrittis, creates its own reality and blinds us to a very different, another reality out there. It is clear that our "intelligent" mind has a bewildering limitation: it interprets things partially and selectively. The context determines the meaning of everything for us. In its usual mode of existence, our mind cannot let go of its conditioned way of thinking and fails to notice shamanic and entheogenic messages boldly displayed within the erotic scenes.

This essay reveals that at least some sculptures in Khajuraho, which look damaged, are actually not damaged, but made to appear so to encode messages. The number of such sculptures is by no means insignificant. Like the display of bizarre contortions and transposition of limbs, these may be a pointer toward spiritual experiences.

It is true that some temples of Khajuraho were destroyed in the past, which is evident from the isolated sculptures stored in the museums and a broken Buddhist temple in the village. Ibn Battuta, who visited India in the 14th century, alleged that Khajuraho Temples contained idols that the Muslims had mutilated (Mitra, 2002). Isn't it possible that he too was confused, like most of us today, about the "damage" inflicted on the idols because he was unaware of the entheogenic meaning of the icons and the dismemberment concept of shamanism?

There is no proof that the Khajuraho Temples were initially "Hindu" (Brahmanical) and they were vandalized by the Muslims. On the contrary, some authors (Jamanadas, 1991) claim that the Buddhists and Jain Temples in India were usurped and even vandalized by the Hindus (Brahmanical sects). Some others opine that this practice is still silently existing in modern India (what happened to 84,000 Stupas/Viharas built by Samrat Ashoka?; http:// velivada.com/2017/05/02/what-happened-to-84000-stupasviharas-built-by-samrat-ashoka/). The Khajuraho Temple's architecture, iconography, pantheon of divinities are the same in all the temples, and all sculptures look similar to the statues stored in the Jain Museum. Does not it mean that Jains originally built these temples? It is worth bearing in mind that Jainism is as old as Brahmanism, but the major difference between the two ideologies is that there is no caste system in Jainism (and Buddhism), which probably was the main reason of persecution of Jains and Buddhists in India. Isn't it possible that Khajuraho Temples were built by the Jains (and perhaps Buddhists?) to show that the way to the God went through the entheogens?

The point we wish to make in this essay is that Brahmanical, Jain, and Buddhist deities are associated with entheogens. It is not clear how and when we forgot our entheogen connection, conflicting among ourselves, and made the mistake of defining religiousness with the construction, destruction, or conversion of holy places. This harm done by organized religion can be undone only by highlighting the entheobotany of spirituality. Understanding the importance of entheogens as a holy sacrament can offer the secular forces of the world an alternative way to deal with religion, and free mankind from the clutches of superstition, dogma, and bigotry. 
The Khajuraho Temples represented the home of Gods, where the body of the entheogen God was ingested by the partaker to leverage faith with rationality, and to learn that the way to God went through our own mind. Their message is: we are the temple, we are the priest, and we are the God who we are searching for through the tenets of our different religions.

Acknowledgements: The authors would like to thank John W. Allen for permission to use Psilocybe cubensis photos and for useful discussions regarding identification of mushroom representations. MM-G is highly indebted to Prof. MW without whose help and guidance this essay could not have been possible. Prof. MW took the ideas of an amateur like MM-G, a complete stranger to him. He worked with MM-G on the essay for almost a year during which he consulted his friends and colleagues about the mushroom sculptures in the temples, provided her with a rich supply of research documents, and made significant contribution to the essay, especially with his writings on shamanic dismemberment, features of entheogenic mushrooms, and the historical record of their usage. Finally, he rewrote the whole essay, beautifully blending the ideas and styles together. He has done everything to ensure that the hidden aspects of Khajuraho Temples become visible to the world. MM-G states that she hopes this essay will prove to be the stepping stone for a major study on Khajuraho, in which she will again have the honor to collaborate with this sacred scholar.

Conflict of interest: The authors received no compensation for this research and have no conflicts of interest.

\section{REFERENCES}

Bennett, C. (2010). Cannabis and the soma solution. Walterville, OR: Trine Day.

Bowman, R. (1970). Aramaic texts from Persepolis. Chicago: The University of Chicago Press.

Crowley, M. (2015). Umbrellas, wheels, and bumps on the head: A proposed solution to the Uṣnịșa mystery. Time \& Mind, 8(2), 191-218. doi:10.1080/1751696X.2015.1026028

Crowley, M. (2016). The secret drugs of Buddhism. Hayfork, CA: Amrita Press.

Dannaway, F. (2009). Thunder among the pines: Defining a panAsian soma. Journal of Psychoactive Drugs, 41(1), 67-84. doi:10.1080/02791072.2009.10400676

Desai, D. (1996). The religious imagery of Khajuraho. Mumbai: Franco-Indian Research Pvt. Ltd.

Desai, D. (2007). Textual tradition and the temples of Khajuraho. Paper presented at Oxford Conference, New Delhi, pp. 20-21.

Eliade, M. (1964). Shamanism: Archaic techniques of ecstasy. New York: Pantheon Books.

Flattery, D., \& Schwartz, M. (1989). Haoma and harmaline: The botanical identity of the sacred hallucinogen "Soma" and its legacy in religion, language, and Middle Eastern folklore [California publications in ancient near Eastern Studies]. Berkeley: University of California.
Flück, M. (2009). Welcher Pilz ist das? (Auflage: 2) [Which mushroom is that?] (2nd ed.). Stuttgart, Germany: KOSMOS Franckh Kosmos Verlag.

Guzmán, G., Allen, J., \& Gartz, J. (1998). A worldwide geographical distribution of the neurotropic fungi, an analysis and discussion. Annali dell Museo Civico di Rovereto Sezione, 14, 189-280.

Hajicek-Dobberstein, S. (1993). Soma siddhas and alchemical enlightenment: Psychedelic mushrooms in Buddhist tradition. Journal of Ethnopharmacology, 48(1995), 99-118.

Harding, D. (2002). On having no head. Zen and the rediscovery of the obvious. Carlsbad, CA: Inner Directions.

Jamanadas, K. (1991). Tirupati Balaji was a Buddhist Shrine. Dalit E-Forum. Chandrapur, India: Sanjivan Publications.

Laughlin, C., McManus, J., \& d'Aquili, E. (1992). Brain, symbol and experience toward a neurophenomenology of consciousness. Boston, MA/Shaftesbury, UK: Shambhala. (Reprinted by Columbia University Press)

Mahdihassan, S. (1983). Identifying the Soma plant as Ephedra from Rigveda and Avesta. Hamdard-Medicus, 26(3), 51-65.

McKenna, T. (1993). Food of the Gods: The search for the original tree of knowledge. A radical history of plants, drugs and human evolution. New York, NY: Bantam Books.

Merlin, M. (2003). Archaeological evidence for the tradition of psychoactive plant use in the old World. Economic Botany, 57(3), 295-323. doi:10.1663/0013-0001(2003) 057[0295:AEFTTO]2.0.CO;2

Merlin, M. (2013). Some aspects of the traditional use of Ephedra species in eastern Eurasia. Ethnobotany, 25(1-2), 1-17.

Merlin, M. (2018). Ancient use of Ephedra in Eurasia and the Western Hemisphere. In S. Fitzpatrick (Ed.), Ancient psychoactive substances (pp. 71-111). Gainesville, FL: University Press of Florida.

Mitra, S. (Ed.). (2002). Khajuraho. Archaeological survey of India. New Delhi, India: Good Earth Publications, Eicher Good Earth Limited.

Monier-Williams Sanskrit-English Dictionary. (1899). MonierWilliams Sanskri-English Dictionary. Retrieved from http:// www.sanskrit-lexicon.uni-koeln.de/scans/MWScan/2014/web/ webtc $2 /$ index.php

Rätsch, C. (2005). The encyclopedia of psychoactive plants: Ethnopharmacology and its applications (J. Baker, Trans.). Rochester, VT: Park Street Press. (Originally published 1998, Enzyklopädie der psychoaktiven Pflanzen. Aarau, Switzerland: AT Verlag.)

Saar, M. (1991). Entheomycological data from Siberia and North-east Asia on the effect of Amanita muscaria. Journal of Ethnopharmacology, 31, 157-173. doi:10.1016/0378-8741(91)90002-u

Schurr, T. (1995). Aboriginal Siberian use of Amanita muscaria in shamanistic practices: Neuropharmacological effects of fungal alkaloids ingested during trance induction, and the cultural patterning of visionary experience. Curare, 18(1), 31-65.

Walsh, R. (1990). The spirit of shamanism. Los Angeles, CA: Tarcher.

Wasson, G. (1968). Soma divine mushroom of immortality. New York, NY: Harcourt, Brace \& World.

Wasson, G. (1971). The soma of the Rig Veda: What was it? Journal of the American Oriental Society, 91(2), 169-187. doi: $10.2307 / 600096$

Winkelman, M. (2010). Shamanism: A biopsychosocial paradigm of consciousness and healing. Santa Barbara, CA: ABC-CLIO. 